\title{
Slab Track Behaviour under Train Passage and Hammer Impact - Measurements at Different Sites and Calculated Track Interaction with Continuous Soils
}

\author{
Lutz Auersch and Samir Said \\ Federal Institute of Material Research and Testing, Berlin, Germany.
}

(Received 25 April 2019; accepted 2 August 2019)

This contribution intends to give an overview on the vibration behaviour of slab tracks in comparison of measurements and calculations and also by comparison of different track types at more than ten different measuring sites. In theory, tracks on continuous soil are calculated by the frequency-wavenumber domain method. In experiment, geophone measurements are transformed to displacement results. Two aspects of track behaviour are considered, the frequency-dependant compliance of the track, measured by hammer impact, and the deflection under a passing axle load. In theory, the response to a single axle can be calculated, whereas in experiment, only the passage of the whole train can be measured. For comparison of theory and experiment, the calculated deflection under a single axle is superposed to get the response of the whole train. As a result, the slab track characteristics are completely different from the ballast track characteristics where each axle can be seen in the time histories. The slab track has a more global behaviour where only a whole bogie can be found in the track response and moreover, the two neighbouring bogies are not completely separated. The measurement of the different track elements (rail, sleeper, track plate, base layer) and the frequency-dependant compliances with possible resonances yield further information about the properties of the track elements. The calculations show that the soil has the dominant influence on the amplitudes and the width of the track-plate displacements. In the measurement results, the following parameters are analysed: slab track vs. ballast track, different types of slab tracks, damaged slab tracks, different trains, switches at different measuring points, voided sleepers, an elastic layer, the mortar layer, and different soils at different places. Finally, a good agreement between measured and calculated results is found for the normal and some special (damaged, floating) slab tracks.

\section{NOMENCLATURE}

a width of the track

$D$ damping (of the rail pad)

EI bending stiffness

EI bending stiffness

$f$ frequency

$F$ force

$F^{\prime} \quad$ force per track length

F force vector auch F'? xx

$G \quad$ shear modulus of the soil

$H_{S} \quad$ compliance of the soil for a plane wave

$H_{S}$ ' compliance of the track-soil interface for wave along the track

$k_{R} \quad$ stiffness of the rail pad

K' stiffness matrix of the elastic track elements

$\mathbf{K}_{\mathrm{S}}$ dynamic stiffness matrix of the soil

$\mathbf{K}_{\mathrm{T}}$ dynamic stiffness matrix of the track

$\mathbf{K}_{\mathrm{TS}}$ dynamic stiffness matrix of the track-soil system

$l_{A} \quad$ axle distance in a bogie

$l_{B} *$ distance of two neighbouring bogies

$m$ ' mass per length

m' mass per length matrix

$p_{1} \quad$ wavenumber transform of the uniform force distribution across the track

$t$ time

$t_{P} \quad$ thickness of the track plate

$u$ displacement

u displacement vector $\mathrm{xx}$ uT?
$v_{S}$ shear wave velocity of the soil

$v_{T}$ train speed

$x$ coordinate across the track

$y$ coordinate along the track

$\omega$ circular frequency

$\xi_{x}$ wavenumber in across the track

$\xi_{y}$ wavenumber along the track

\section{INTRODUCTION}

Slab track is a track form which becomes increasingly important in railway traffic. Slab track is an alternative track form to the ballast track. The ballast is replaced by a stiff layer which usually is a concrete plate (Fig. 1). By that, the settlement of the ballast is eliminated and the maintenance effort should be reduced. Many lines have been built with slab tracks worldwide but there are still attempts to improve this track form.

The dynamic behaviour of slab tracks is useful for many aspects of railway engineering. Modelling and theoretical results are necessary for the design. ${ }^{1,2}$ The load condition of any track is an important information for understanding the deterioration $^{3}$ and for maintenance decisions. ${ }^{4}$ Track monitoring ${ }^{5}$ can be used to prevent damage. ${ }^{6,7}$ Dynamic measurements can be used to identify track damage $\mathrm{e}^{8,9}$ or general track characteristics. ${ }^{10,11}$ The soil has a strong influence on the slab track behaviour so that the analysis of the substructure ${ }^{12-14}$ has a great value, particularly at transition zones. ${ }^{11,15,16}$ 


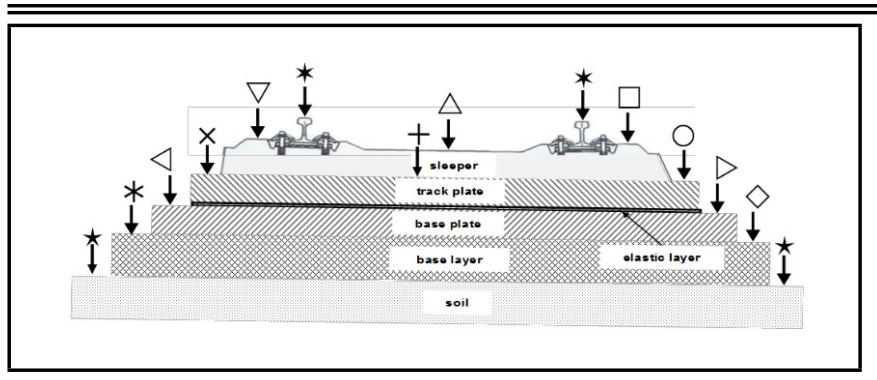

Figure 1. Slab track components and measurement positions at the rail, sleeper, track plate, base plate (or trough) if existing, base layer and the soil.

The Federal Institute of Material Research and Testing (BAM) has performed many measurements of dynamic track behaviour in relation to prototype testing (design) and damage detection. The purpose of the present contribution is to evaluate some of these measurements to illustrate the track behaviour of different tracks at different sites, on different soils. The focus is on normal intact slab tracks and their deflections under train passages and their response under hammer impact. Their behaviour is compared with other track forms and other slab tracks. The observed specific phenomena can be used to calibrate theoretical track-soil models.

Hammer impacts are often used, ${ }^{17,18}$ particularly to verify calculation methods and to evaluate input parameters. ${ }^{19-23} \mathrm{Al}-$ ternative methods are wheelset drop tests ${ }^{24}$ or measurements from a special rail vehicle. ${ }^{25}$ The measurement of train passages is done for monitoring and damage detection ${ }^{9,14}$ and in combination with ground vibration measurements. ${ }^{27-29}$ A special problem in track monitoring is to transform measured accelerations or velocities to track displacements. ${ }^{14,29}$

All measurements should be confronted with calculations. The present article uses wavenumber integrals to describe the deformation of the infinitely long track. ${ }^{19,30-32}$ For damaged tracks, the combined finite-element boundary-element method has been used. ${ }^{9}$ It is necessary to include the infinite continuous soil by wavenumber integrals ${ }^{32}$ or by Green's functions. ${ }^{33}$ Other methods that account for the continuous soil are the finite element method, ${ }^{34-44}$ and combinations of finite and integral methods, called $2.5 \mathrm{D}$ methods. ${ }^{38,39}$ The calculations provide the ranges of the displacements for intact and damaged slab tracks and the influence of the different track and soil parameters.

The novelty of this contribution is to present at the same time:

- measurements of slab tracks and ballast tracks (not only ballast tracks ${ }^{18,20-23,26,29,35-39}$ ),

- measurements of train passages and hammer impacts (not only one measurement type ${ }^{19}$ or pure theory ${ }^{30}$ ),

- measurements of all track components (not only the rail $\left.^{18-23,26,29,35-39}\right)$,

- measurements at several sites (not only one site $^{21-23,26,29,35-39}$ ),

- deflection shapes under train passage (not only axle$\overline{\text { sequence spectra }}^{21,35}$ ),

- amplitude and phase of the receptances (not only amplitudes $^{21,23}$ ),

- calculation of tracks on continuous soil (not only tracks on Winkler soil ${ }^{15,29}$ ),

- parameter studies for hammer impact and train passage (not only one example for verification ${ }^{21,35,36}$ ), a)

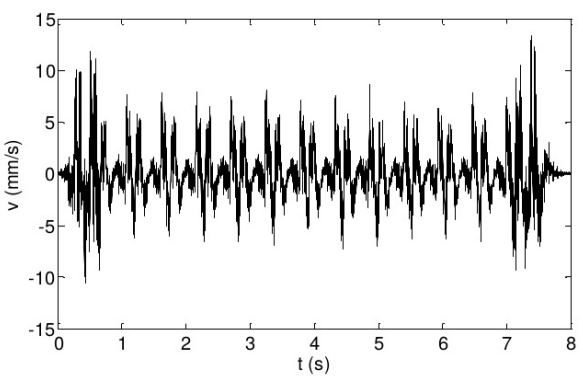

b)

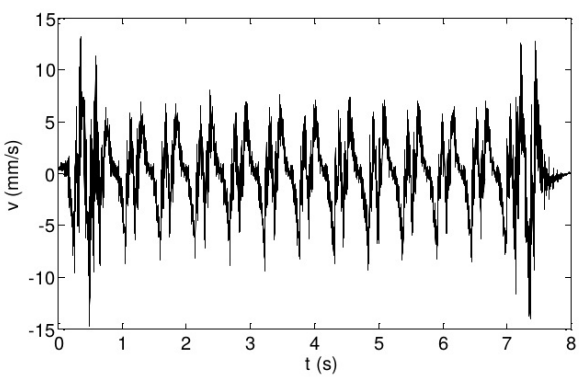

c)

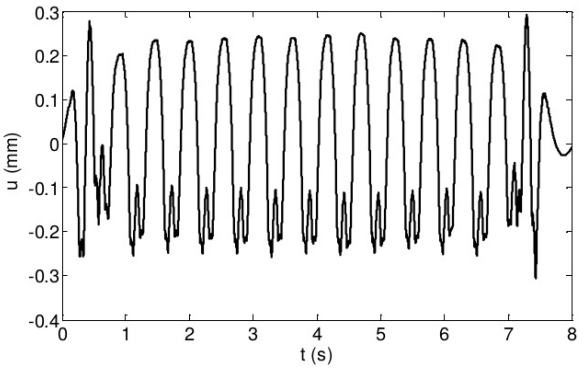

d)

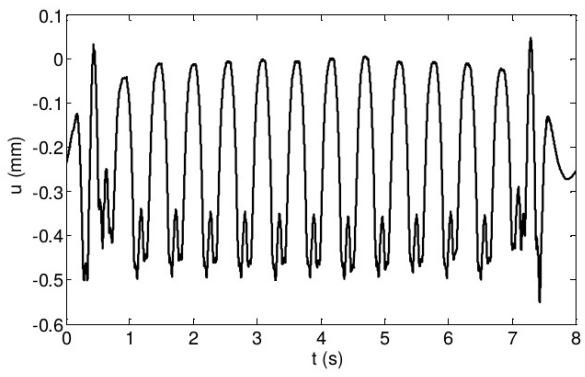

Figure 2. Data processing from a) measured velocities to b) corrected velocities (by geophone transfer function) to c) filtered (frequencies next to zero) and time-integrated velocities and d) displacements after de-shifting (base-line correction); measurement of the track plate at site 1 for a passing ICE1 train.

where typical shortcomings of the state of the art are given in brackets with exemplary references.

The material, which is based on the conference contribution $^{40}$ and which has been considerably extended in theory and experiments, is presented as follows. The measurement methods are presented in Section 2, and the calculation methods in Section 3. The theoretical track response to train passages is analysed in Section 4 for different vehicles, track plates and soils. Section 5 shows the measured results for twelve sites and for normal and special slab tracks. At some of these sites, hammer impacts have been measured (Section 6). The rail, track plate, base plate and base layer response is analysed. The original hammer measurements must be modified to get comparable results for a wheelset excitation. In Section 7, frequencydependent transfer functions of the tracks and track elements have been calculated for different rail pads, track plates and soils. The measured and calculated results of train passages and hammer impacts are compared in Section 8 leading to the final conclusions (Section 9). 


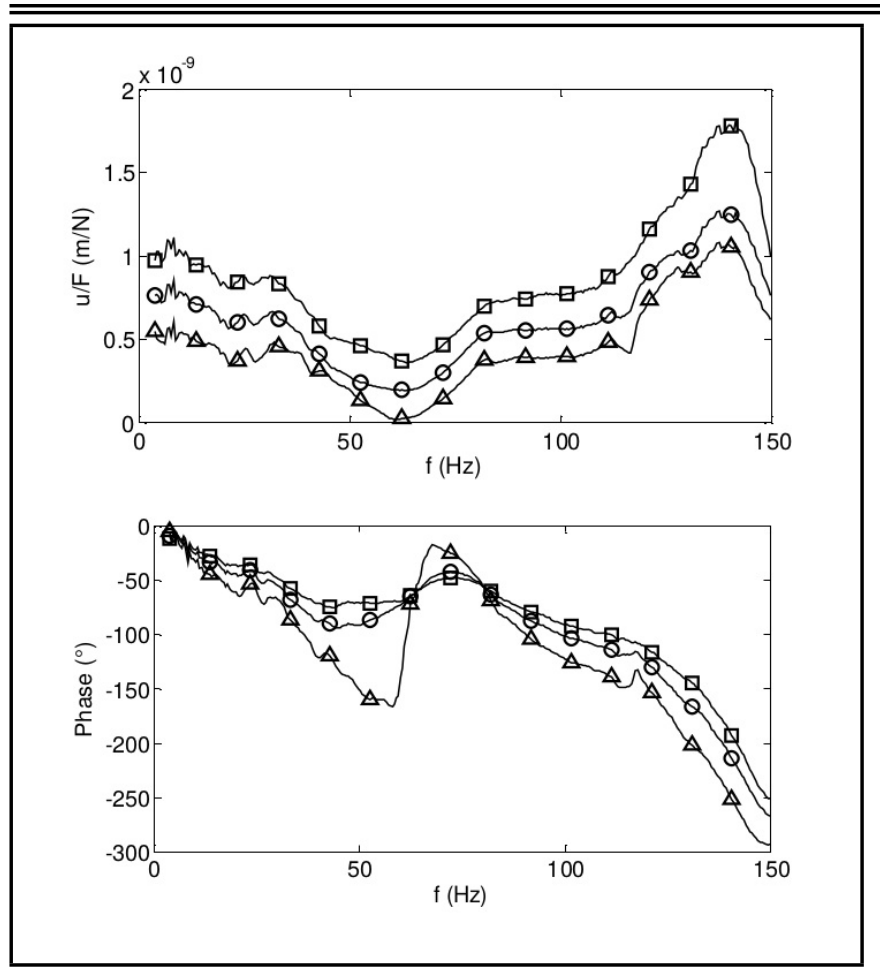

Figure 3. Hammer impact on the right rail of the slab track at site 7, transfer function for the $\square$ right side of the sleeper, $\triangle$ left side of the sleeper, and $\bigcirc$ the average of both (the two-sided transfer function for a wheelset excitation).

\section{METHODS OF TRAIN PASSAGE AND HAMMER IMPACT MEASUREMENTS}

The track vibration during the passage of trains has been measured with velocity transducers (geophones) or accelerometers. The sensors are glued to the track elements or fixed with spikes to the soil. The geophone measurement data (Fig. 2a) have been corrected for the frequency-dependent complex transfer function of the geophones (eigenfrequency 4.5 Hz, Fig. 2b) and then time-integrated to obtain the displacements of the track elements (Fig. 2c). To get stable results for these two steps, the frequency content below $1 \mathrm{~Hz}$ is filtered out by a $5^{\text {th }}$ order Butterworth filter. The time integration results in reduced high frequencies so that no special filter is necessary to filter out the high-frequency content. In addition to the previous steps, a base-line correction is necessary (Fig. 2d), see a similar procedure in. ${ }^{29}$ The results of this procedure have been compared with the results of displacement and laser sensors at several places confirming the good performance, (examples are shown later in Fig. 8).

Using an instrumented hammer, the transfer functions of the track (compliances) and of the soil (admittances) can be evaluated. ${ }^{9}$ Usually, the responses of ten hammer impacts on the unloaded track are averaged, and the standard sampling frequency of $2 \mathrm{kHz}$ is chosen for hammer as well as for train measurements. The impact on the right rail, the left rail or both can be measured giving a one-sided transfer function of the track. Averaging the transfer functions from the left-rail and right-rail impact yields the two-sided transfer function of the track under a wheelset load. Instead of averaging the leftand right-rail impact it is also possible to average the left- and right-side response to a single side impact (Fig. 3). Several tests show that taking the half of the one-sided transfer function for the rail and about 0.7 of the one-sided transfer function for the sleeper and track plate yields an acceptable approxima-

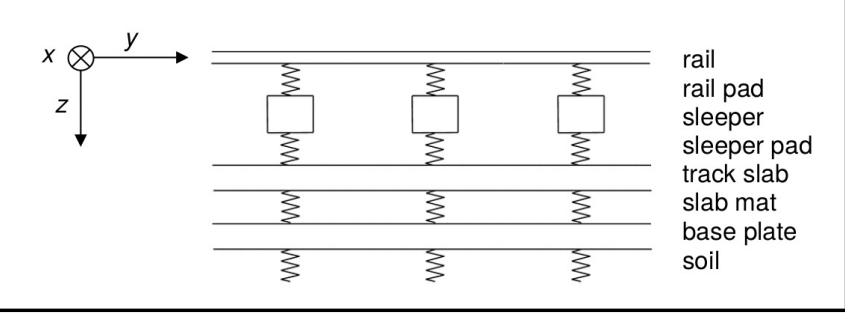

Figure 4. Multi-beam-on-soil model for a slab track with rail pads, sleeper pads or a slab mat (floating slab track).

tion of the two-sided transfer function. Hammer impacts and a measurement line on the soil are also used to determine the wave velocities and the damping of the different soils. ${ }^{41}$

\section{CALCULATION OF TRACK AND SOIL VIBRATION BY WAVENUMBER INTEGRALS}

The slab tracks can also be modelled as multiple-beam systems (Fig. 4). The first beam represents the two rails, the second beam represents the track plate, (and a third beam could be used as the base plate of a floating slab track). Each beam is described by its bending stiffness $E I_{j}$ and its mass per length $m^{\prime}{ }_{j}$, which are assembled in a diagonal stiffness matrix EI and a diagonal mass matrix $\mathbf{m}$ '. The beams are connected by elastic elements (rail pads, slab mats) characterised by complex stiffnesses per track length which are assembled in the global stiffness matrix K'. The multi-beam system fulfils the set of differential equations for the track displacements $\mathbf{u}_{\mathbf{T}}$ (the rail - base vector $\mathbf{e}_{1}$, the track plate - base vector $\mathbf{e}_{2}$ and the base plate - base vector $\mathbf{e}_{3}$ ) under the track load $F^{\prime}{ }_{T}$ (per length)

$$
\mathbf{E I} \frac{\partial^{4}}{\partial y^{4}} \mathbf{u}_{\mathbf{T}}+\mathbf{m}^{\prime} \frac{\partial^{2}}{\partial t^{2}} \mathbf{u}_{\mathbf{T}}+\mathbf{K}^{\prime} \mathbf{u}_{\mathbf{T}}=F^{\prime}{ }_{T} \mathbf{e}_{\mathbf{1}}
$$

This equation is transformed to the frequency-wavenumber domain giving the dynamic stiffness matrix $\mathrm{K}^{\prime}\left(\xi_{y}, f\right)$ of the multibeam track model

$$
\mathbf{K}_{T}^{\prime}\left(\xi_{y}, f\right)=\xi_{y}{ }^{4} \mathbf{E I}-\omega^{2} \mathbf{m}^{\prime}+\mathbf{K}^{\prime}
$$

where $\omega=2 \pi f$ is the circular frequency and $\xi_{\mathrm{y}}$ is the wavenumber along the track axis. This dynamic stiffness matrix must be coupled with the dynamic stiffness matrix of the soil which is calculated as follows.

The soil compliance $u_{S} / F{ }_{S}=H_{S}\left(\xi_{x}, \xi_{y} f\right)$ of a homogeneous or layered half-space can be calculated in frequencywavenumber domain by different matrix methods. ${ }^{42-44}$ This compliance $H_{S}$ for plane waves along the soil surface can be integrated across the track to get the compliance $u_{S} / F^{\prime}{ }_{S}=H^{\prime}{ }_{S}\left(\xi_{y}, f\right)$ of the track-soil interface for waves along the track

$\frac{1}{K_{S}^{\prime}\left(\xi_{y}, f\right)}=H_{S}^{\prime}\left(\xi_{y}, f\right)=\frac{1}{2 \pi} \int_{-\infty}^{\infty} H_{S}\left(\xi_{x}, \xi_{y}, f\right) p_{1}^{2}\left(\xi_{x}\right) d \xi_{x}$

In equation (3), the wavenumber transform

$$
p_{1}\left(\xi_{x}\right)=\frac{\sin \xi_{x} a / 2}{\xi_{x} a / 2}
$$




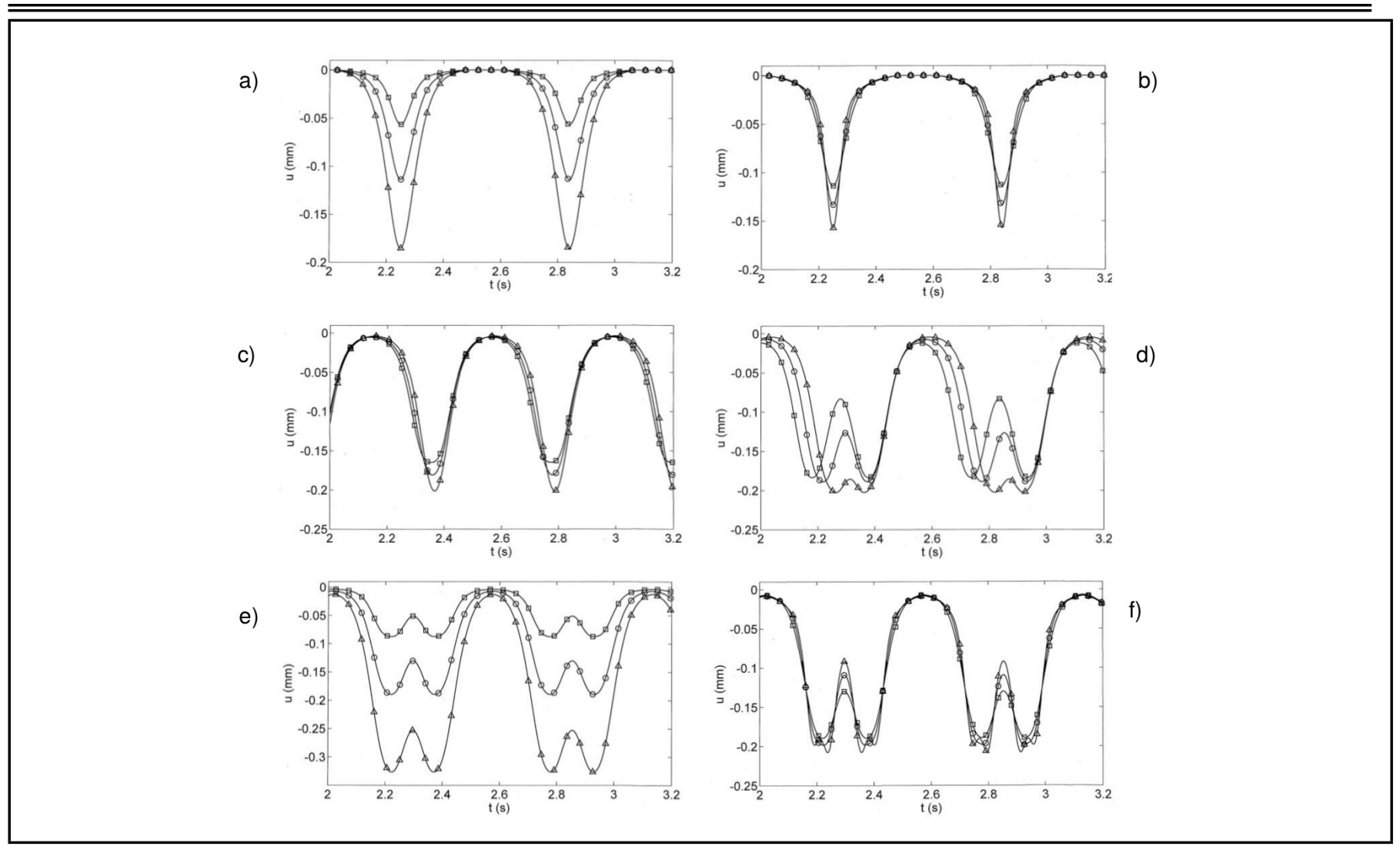

Figure 5. Calculated track plate displacements for passages of axle loads of $100 \mathrm{kN}$ over slab tracks, single axles over a) different soils with shear wave velocity $v_{S}=\triangle 150, \bigcirc 200, \square 300 \mathrm{~m} / \mathrm{s}$, and b) different slabs of thickness $t_{P}=\triangle 0.15, \bigcirc 0.3, \square 0.45 \mathrm{~m}$, c) single bogies with different axle distances $l_{A}=\triangle 1.8$, $\bigcirc 2.5, \square 3 \mathrm{~m}, 1$ and 2 half passenger cars with different d) bogie distances $l_{B} *=\triangle 6, \bigcirc 7.5, \square 9 \mathrm{~m}, \mathrm{e}$ ) different soils $v_{S}=\triangle 150, \bigcirc 200, \square 300 \mathrm{~m} / \mathrm{s}$, and f) different slabs $\left.\left.t_{P}=\triangle 0.15, \bigcirc 0.3, \square 0.45 \mathrm{~m}, \mathrm{a}, \mathrm{c}, \mathrm{d}, \mathrm{e}\right) t_{P}=0.45 \mathrm{~m}, \mathrm{~b}, \mathrm{c}, \mathrm{d}, \mathrm{f}\right) v_{S}=200 \mathrm{~m} / \mathrm{s}$.

of the uniform load distribution across the track width $a$ has been used and the average of the response across the track has been taken. ${ }^{32}$ The inverse

$$
K_{S}^{\prime}\left(\xi_{y}, f\right)=\frac{1}{H_{S}^{\prime}\left(\xi_{y}, f\right)}
$$

the soil stiffness $K_{S}$, per track length, is used for coupling the soil with the track as

$$
\mathbf{K}^{\prime}{ }_{\mathrm{TS}}\left(\xi_{y}, f\right)=\mathbf{K}_{T}^{\prime}\left(\xi_{y}, f\right)+\mathbf{e}_{3} K^{\prime}{ }_{S}\left(\xi_{y}, f\right) \mathbf{e}_{3}{ }^{T}
$$

and the dynamic stiffness matrix $\mathbf{K}_{\text {TS }}^{\prime}\left(\xi_{y} f\right)$ of the track-soil system is established.

The displacements in the frequency-wavenumber domain are calculated by the inversion of this matrix

$\mathbf{u}_{T}\left(\xi_{y}, f\right)=\mathbf{K}_{\mathrm{TS}}^{\prime}\left(\xi_{y}, f\right)^{-1} \mathbf{F}_{T}=\mathbf{K}_{\mathrm{TS}}^{\prime}\left(\xi_{y}, f\right)^{-1} F_{T}\left(\xi_{y}, f\right) \mathbf{e}_{1} ;$

and the wavenumber transform $F^{\prime}{ }_{T}\left(\xi_{\mathrm{y}}, \omega\right)$ of the excitation force on top of the track. Finally, the displacement distribution along the track can be calculated by the Fourier integral of the wavenumber domain solution

$$
\mathbf{u}_{T}(y, f)=\frac{F_{T}(f)}{2 \pi} \int_{-\infty}^{\infty} \mathbf{K}_{\mathrm{TS}}^{\prime}\left(\xi_{y}, f\right)^{-1} \mathbf{e}_{1} \exp \left(i \xi_{y} y\right) d \xi_{y}
$$

where the special constant wavenumber transform of a point load

$$
F^{\prime}{ }_{T}\left(\xi_{y}, f\right)=F^{\prime}(f)
$$

has been introduced.

\section{CALCULATED SLAB DISPLACEMENTS UNDER TRAIN PASSAGES}

The displacements along the track ( $y$-axis) can be transformed to time histories (time $t$ ) of a train passage by superposing several axles and using the train speed $\mathrm{v}_{\mathrm{T}}$ for $t=y / v_{T}$. Figure 5 shows results for a Talgo train with single axles, a Thalys train with single bogies and an ICE3 train with two bogies per carriage. The displacements of a single axle strongly depend on the stiffness of the soil (Fig. 5a) and less strongly on the bending stiffness of the track (Fig. 5b). The deflection of the track is wider for a soft soil, but narrower for a soft track. The response of a single bogie (Fig. 5c) is stronger than the response of a single axle (Fig. 5a, circle marker) as one axle yields also displacements for the second axle of the bogie (interaction between the two axles). There is only one deflection of the track plate for the two axles of a bogie. The bogie displacement can be almost twice of the axle displacement if the axle distance is short for a freight car $(1.8 \mathrm{~m}$, Fig. $5 \mathrm{c}$, triangle marker, 0.2 instead of $0.12 \mathrm{~mm}$ ). The long bogie of a locomotive $(3.0 \mathrm{~m})$ has a wider deflection and a lower maximum of $0.15 \mathrm{~mm}$. The interaction of two neighbouring bogies can be seen in Fig. 5d. The shape of the track response changes with the separation between the two bogies. Namely the displacement in the middle of the two bogies is quite different. For a narrow bogie separation $(6 \mathrm{~m})$, the inter-bogie displacement $(0.19 \mathrm{~mm})$ is not much smaller than the axle displacement. For a long bogie separation $(9 \mathrm{~m})$, the inter-bogie displacement $(0.1 \mathrm{~mm})$ is about half the axle displacement, and for the ICE3 $(7.5 \mathrm{~m})$, it is about two thirds $(0.14 \mathrm{~mm})$. Finally, the influence of the soil and track stiffness on the response of an ICE3 train 
a)

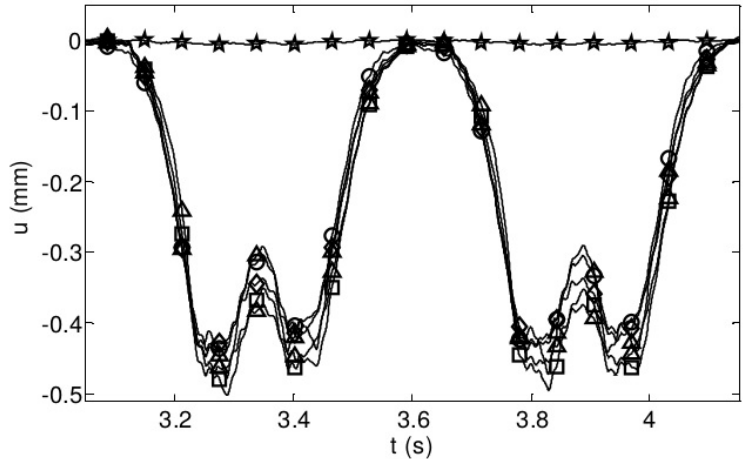

c)

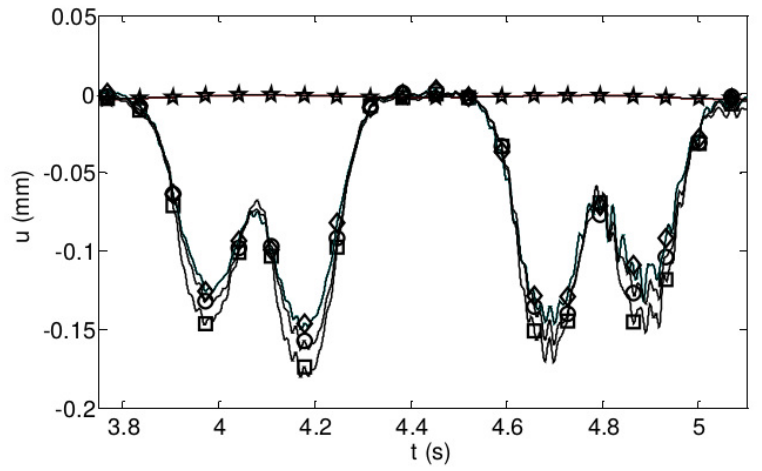

e)

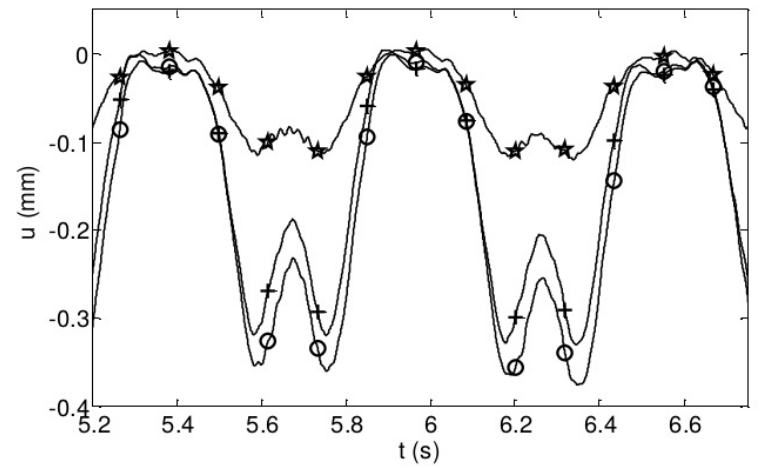

g)

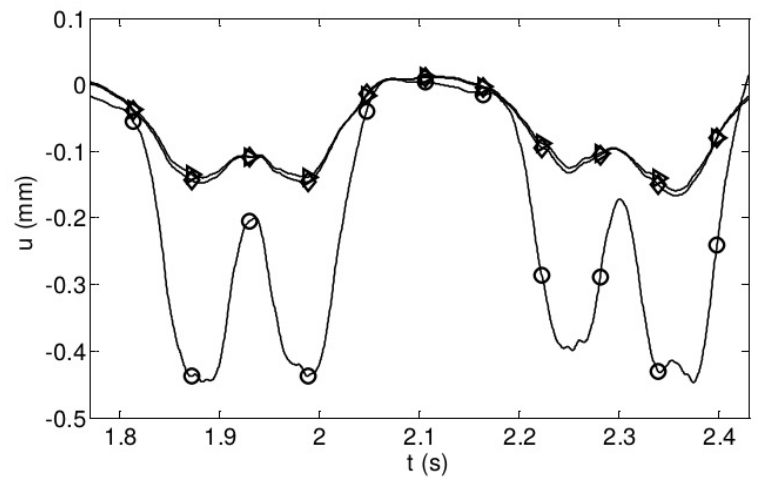

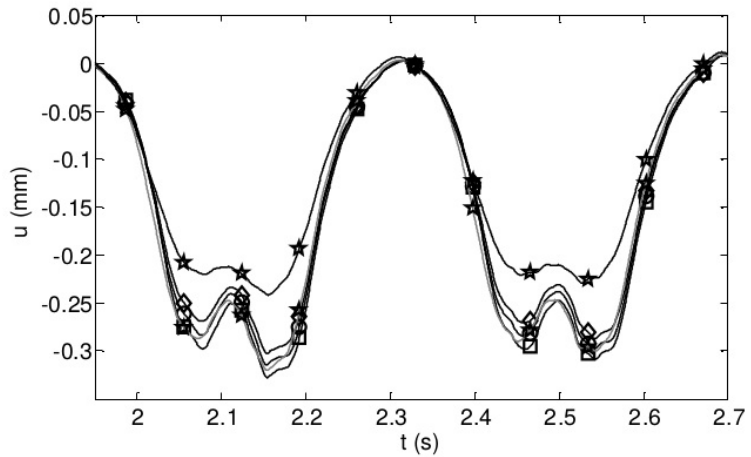

b)

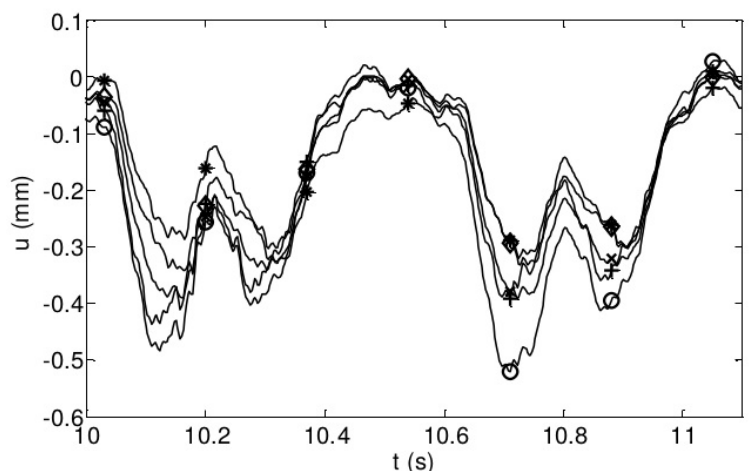

d)

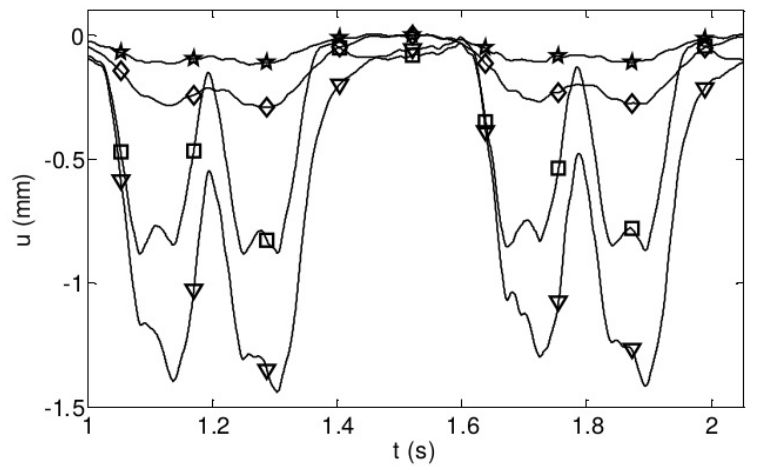

f)

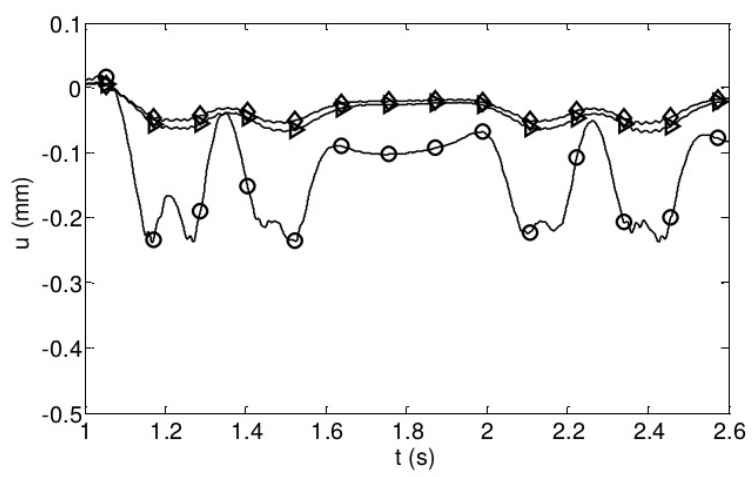

h)

Figure 6. Measured passages of 1 and 2 half passenger cars over normal slab tracks a-d) at sites 1-4, e,f) at site 5 with concrete and asphalt slab track, g,h) floating slab track at site 6 with normal and stiff soil; ICE or IC (c) trains. Measurement points $*$ rail, sleeper $(\square$ right, $\triangle$ mid, $\nabla$ left), track plate $(\bigcirc$ right, + mid, $\times$ left), base plate (trough) $(\triangleright$ right, $\triangleleft$ left), base layer $(\diamond$ right, $*$ left), $\star$ soil.

( 1 and 2 half passenger cars) is analysed in Figs. 5e,f. The influence of the soil on the maximum displacement is very strong (Fig. 5e), $u_{3} / u_{1}=0.33 / 0.08 \approx 4=G_{l} / G_{3}$, whereas the influence of the track bending stiffness is very weak (Fig. 5f), $u_{3} / u_{1}$ $=0.36 / 0.33 \approx 1.12<<27=E I_{1} / E I_{3}$, weaker than for a single axle (Fig. $5 b$ ). The soft track with a thin plate yields less interaction between the bogies and a more local behaviour with narrower deflections and with lower inter-bogie displacements, and in addition, a maximum for each axle occurs (Fig. $5 \mathrm{f} \mathrm{tri-}$ angle marker). The soft track with its more local behaviour is an exception between the normal slab tracks which all have a typical global deflection behaviour. 
a)

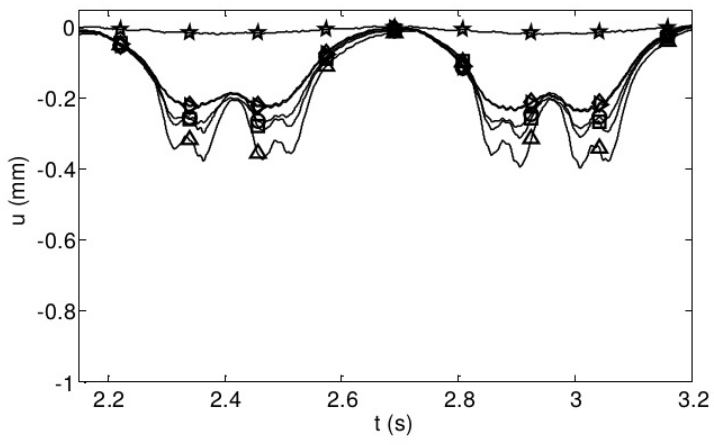

c)

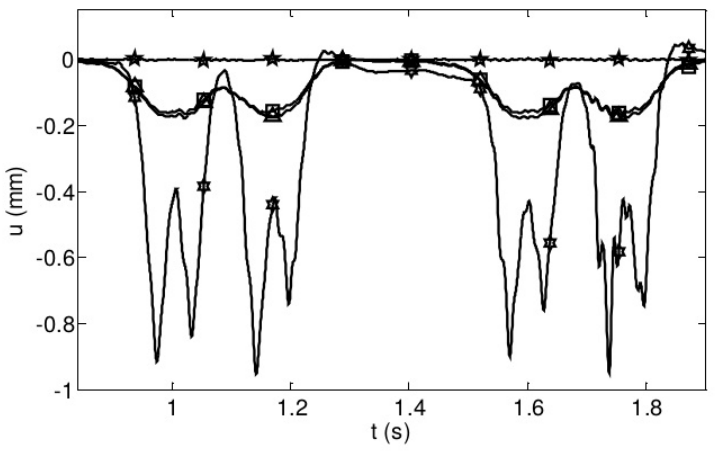

e)

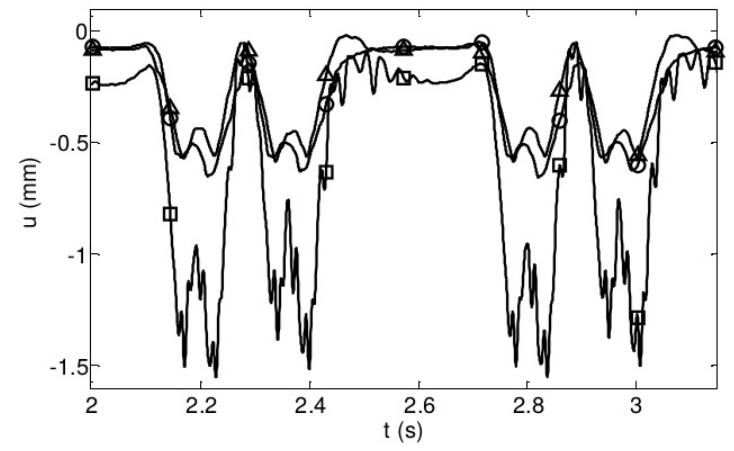

g)

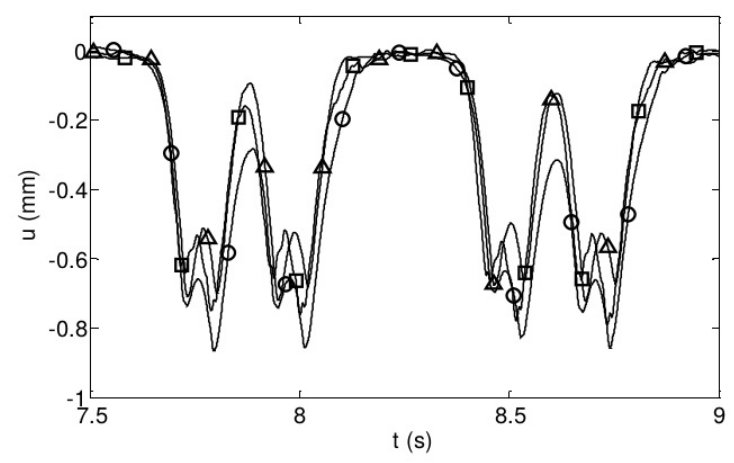

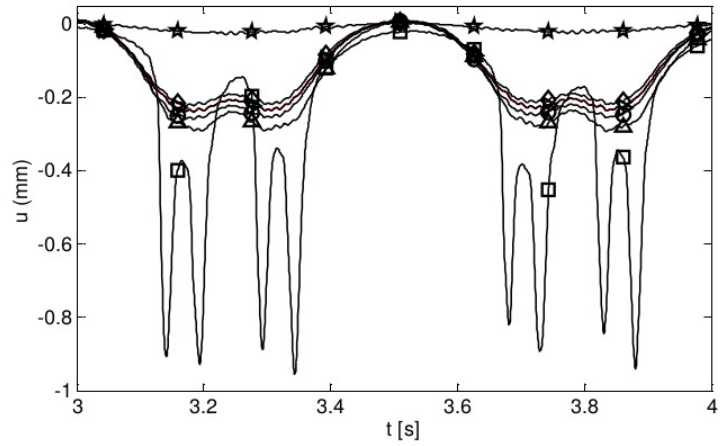

b)

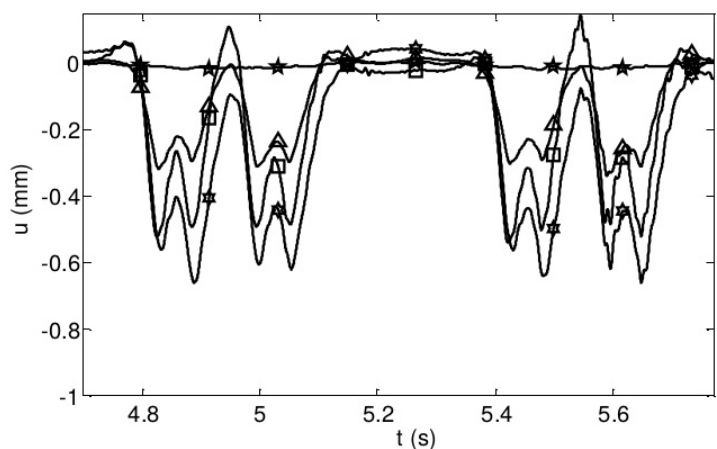

d)

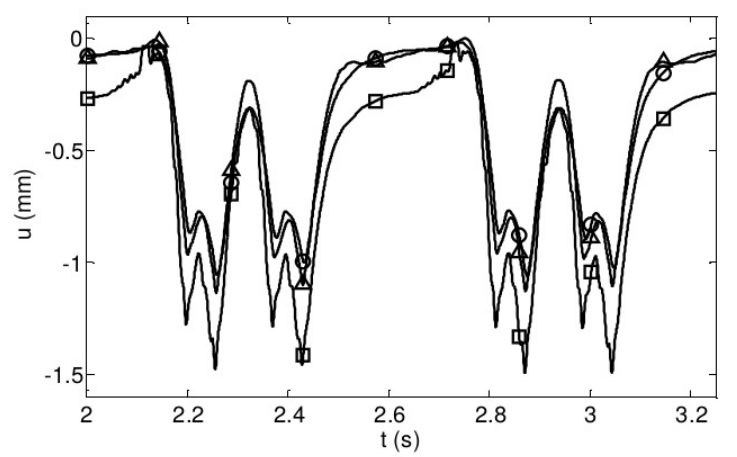

f)

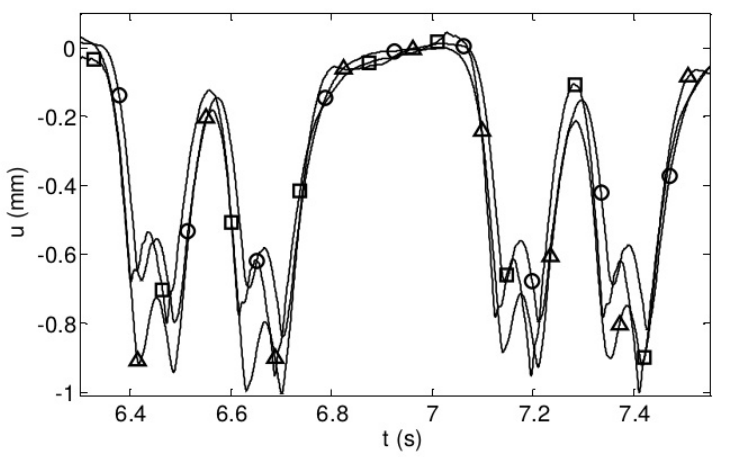

Figure 7. Measured passages of 1 and 2 half passenger cars over an "intact" (a) and a damaged (b) slab track (lose sleeper) at site 1, a slab track (c) and a ballast track (d) at site 7, measurement points $*$ rail, sleeper ( $\square$ right, $\triangle$ mid, $\nabla$ left), track plate ( $\bigcirc$ right, + mid, $\times$ left), base plate (trough) ( $\triangleright$ right, $\triangleleft$ left), base layer $(\diamond$ right, $*$ left), $\star$ soil; a switch on ballast track without (e,g) and with under-sleeper pads (f,h) at site 8 and site $9, \square$ begin, $\bigcirc$ mid, and $\triangle$ end of the switch, a,b) ICE trains, c-h) IC trains.

\section{MEASURED DISPLACEMENTS PASSAGES \\ TRACK TRAIN}

The response of different slab tracks to passing trains measured at different sites are shown in Figs. 6 and 7. For each situation, the responses of different measurement points are given in one sub-figure. In the first four Figs. 6a to 6d, normal slab tracks on "normal" soils (wave velocities between 150 and 225 $\mathrm{m} / \mathrm{s}$ ) are presented. In general agreement, the maximum displacements of the sleeper or track plate under an ICE train are in the range of $u_{\max }=0.3-0.5 \mathrm{~mm}$. Figures $6 \mathrm{c}, 7 \mathrm{c}$ for the passage of an IC train have lower amplitudes due to lower axle loads.

As in Fig. 5, one and two half carriages are shown in each sub-figure, and four deflections for four bogies are present. The measurement results have more irregularities, and namely small vibrations due to the sleeper-distance excitation can be 


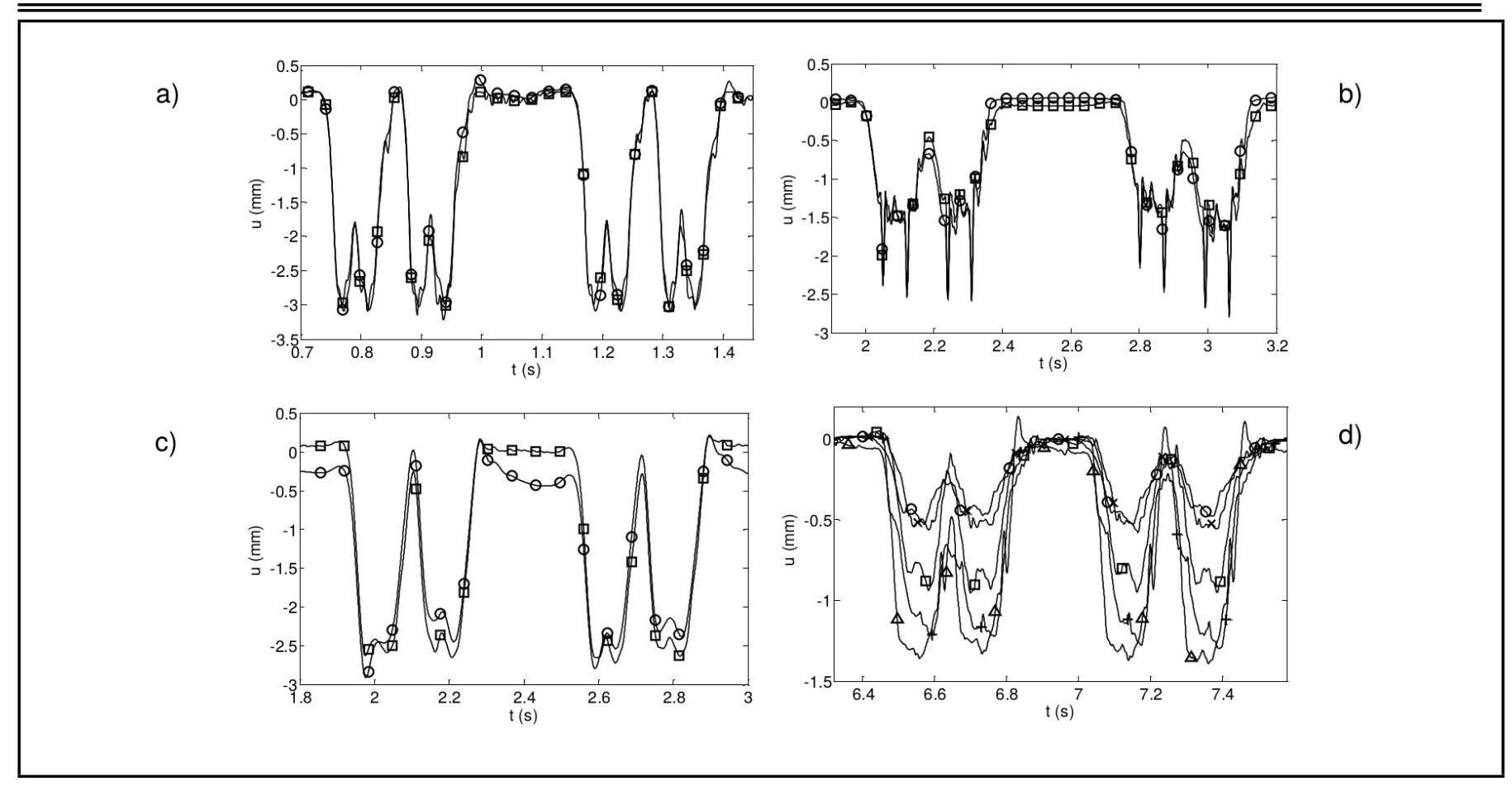

Figure 8. Measured passages of 1 and 2 half passenger cars over switches with voided sleepers at a) site 10, b) site 11, c,d) site 12, $\square$ sleeper displacements from displacement sensor, $\bigcirc$ sleeper displacements from accelerometer, d) displacements of sleeper $\square-6, \bigcirc-4, \triangle-2,++4, \times+6$ indicating a void under all these sleepers.

a)

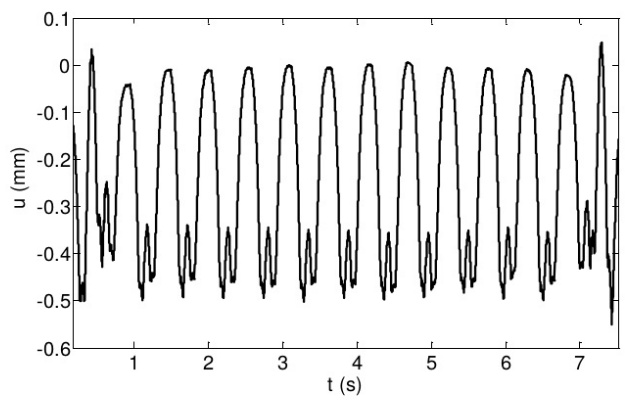

c)

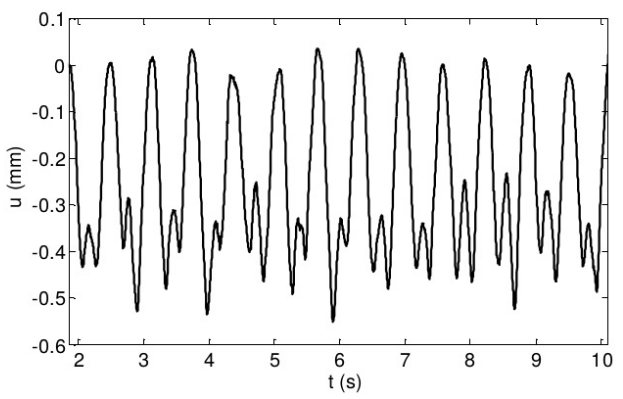

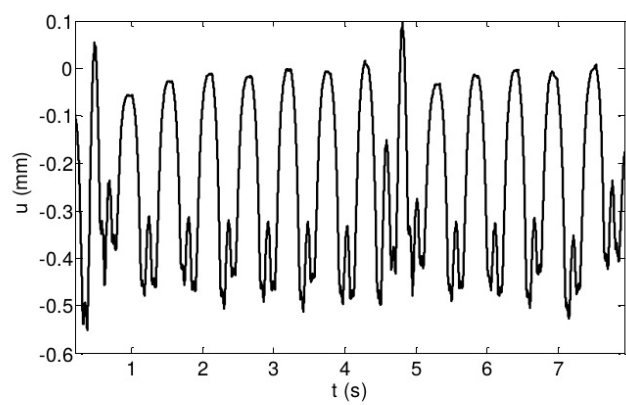

b)

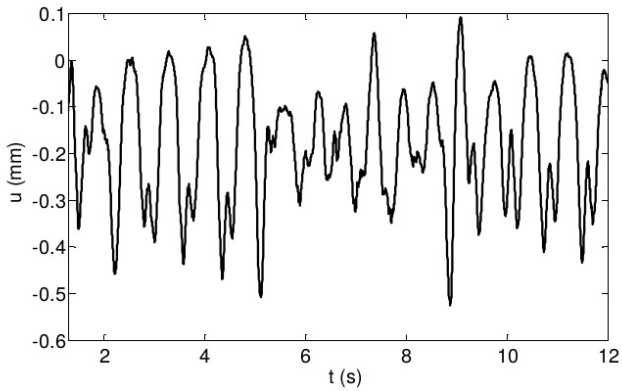

Figure 9. Slab track displacements (track plate) measured under different trains, a) ICE1, b) ICE2, site 1, c) freight train with equally loaded carriages, d) freight train with different and variably loaded carriages, site 4 .

found. The inter-bogie displacements vary between $50 \%$ and $80 \%$ of the maximum displacement. For normal slab tracks, all measurement points of the track layers (sleepers, track plate, base plate, base layer) have very similar amplitudes from top to bottom of the track. The amplitudes of the soil are much smaller, and the rail has much higher amplitudes in case of a slab track (Fig. 7c). The side- and mid-points of the same track element show sometimes different amplitudes (for example Figs. 6f, 7d) so that some deformation across the track or a rotation of the track can be concluded.
Two special slab tracks are presented in Figs. 6f-h, both having an additional elastic layer within the track. Figure $6 \mathrm{f}$ shows a slab track where an asphalt layer is used instead of the track plate. Corresponding to the soft asphalt, the displacements of the base layer under the asphalt are only $30 \%$ of the maximum of the sleepers which is $0.8-1.4 \mathrm{~mm}$, the highest of all measured slab tracks. Moreover, each axle can be seen as a small maximum. The slab track of Figs. $6 \mathrm{~g}$, h includes a rubber granulate layer between track plate and base plate. Therefore, the amplitude of the base plate is much lower, only $25 \%$ of 
the track plate amplitude of $0.45 \mathrm{~mm}$. This special slab track structure has been measured at two sites with very different soils. The soil at the second site (Fig. 6h) was much stiffer including some rock material so that the amplitudes of the same track and the same train were much smaller, 0.2 instead of 0.45 $\mathrm{mm}$.

Figures 7a,b show an intact (repaired) and a damaged slab track where the track plate was loosened from the base layer. This can clearly be seen by the high amplitudes $(0.9 \mathrm{~mm})$ of the lose track plate for each axle passage. The amplitudes of the elements below the gap are somewhat smaller than those of the intact track (Fig. 7a, $0.3 \mathrm{~mm}$ ). The damage and the repair could be checked at some sites by this kind of measurements.

The slab track has been compared to a ballast track in Fig. 7c,d where the different tracks have been measured for the same IC-train passage at two consecutive sections. The low amplitudes of the track plate $(0.17 \mathrm{~mm})$ are highly exceeded by the amplitudes of the sleeper on the ballast $(0.3-0.5 \mathrm{~mm}$, the difference between side- and mid-sleeper point indicate a considerable sleeper bending). The ballast track reacts with separate bogie responses and with two axle maxima for each bogie. This local behaviour is also found for the rails of both track systems. The rail amplitudes are higher for the slab track, $0.8 \mathrm{~mm}$ compared to $0.6 \mathrm{~mm}$ for the rail of the ballast track.

Ballasted tracks with switches are shown in Figures 7e-h. At site 8, a normal switch (Fig. 7e) has been compared with a switch on rather stiff under-sleeper pads (Fig. 7f). High amplitudes of $1.5 \mathrm{~mm}$ have been measured at the end of the switch (the nose) whereas normal amplitudes of $0.6 \mathrm{~mm}$ have been measured at the beginning and the mid of the switch. The switch with under-sleeper pads shows two times higher amplitudes at these points so that all switch points have the same level. A similar effect of slightly increased amplitudes can also be seen at site 9 for the switch with stiff under sleeper pads (Fig. 7h) compared to the normal switch (Fig. 7g).

Figure 8 shows switches over a void between sleeper and ballast. This damage causes high sleeper amplitudes of 2.5 to $3 \mathrm{~mm}$. The passage of the axles, however, are quite different at these three sites. Figure 8 a shows high amplitudes but quite normal time histories as for intact ballast tracks. Each axle can clearly be seen and the amplitudes return to zero between the bogies. Figure $8 \mathrm{~b}$ shows a case with very short axle impulses indicating probably a very local defect, maybe a void under only one sleeper. At the last site (Fig. 8c,d), the axle impulses are not so clear, the deformation is wider. This could be understood as a void under many sleepers which has been confirmed by the measurement of higher amplitudes also at the $-6^{\text {th }}$ to $+6^{\text {th }}$ sleeper (Fig. 8d).

The analysis of different tracks and different sites is complemented with the analysis of different trains (Fig. 9). Two different ICE trains yield almost identical responses of the slab track. The ICE1 consists of a locomotive +12 carriages + locomotive whereas the ICE2 consists of two coupled half trains with locomotive +6 carriages +1 end car where the axle loads of the locomotive are higher and the axle distance is longer ( 3 $\mathrm{m})$. The different behaviour under the locomotive can clearly be found in the time histories (around $4.7 \mathrm{~s}$ ), and the longer inter-bogie distance (at $4.5 \mathrm{~s}$ ) between end car and locomotive is indicated by the lower inter-bogie displacement. Figures 9c and $8 \mathrm{~d}$ show freight trains with equally or variably loaded carriages. The maximum displacement is slightly higher than for the ICE trains at this site (Fig. 9d).

\section{COMPLIANCE FUNCTIONS MEASURED UNDER HAMMER IMPACT}

The hammer impact measurements have been evaluated for the complex transfer functions (amplitude and phase of the compliance) of all measurement points (Fig. 10a,b) and for all measurement sites (Fig. 11a,b). The compliance of the track is higher for the asymmetric one-sided hammer impact compared to the symmetric wheelset excitation of the preceding sections. At site 7 (Fig. 10a), all points of one side yield similar transfer functions, where the excited side has about twice the amplitudes. All track points at this site show a minimum at about $65 \mathrm{~Hz}$ and a maximum at $140 \mathrm{~Hz}$ which is the resonance of the rail on the rail pads.

The same detailed measurements and evaluations have been done at site 3 (Fig. 10b). Here, the results indicate a slab track damage. Sleeper, track plate and base layer show different and somewhat higher amplitudes. Namely the sleeper amplitudes are considerably higher than what normally has been measured.

The rail points of six different sites are presented in Fig. 11a. Four of these sites have nearly the same resonance at $140 \mathrm{~Hz}$ indicated also by a crossing of four phase curves at $-90^{\circ}$. Site 3 has its resonance at $215 \mathrm{~Hz}$ (not present within the given frequency range), and site $5 \mathrm{~b}$ has a lower resonance at $90 \mathrm{~Hz}$ due to very soft rail pads. The static compliances of the rail are between 1 and $210^{-8} \mathrm{~m} / \mathrm{N}$, which would be 0.5 to $110^{-8} \mathrm{~m} / \mathrm{N}$ for the two-sided wheelset excitation in agreement with the trainpassage result in Fig. 6c. The compliances of the track plate (Fig. 11b) are much lower, starting at 1 to $2.510^{-9} \mathrm{~m} / \mathrm{N}$. The rail-on-rail-pad resonance can be found also at the track plate, but not so clear and with an anti-phase, see for example site $5 \mathrm{~b}$ with the lowest resonance frequency of $90 \mathrm{~Hz}$ and a strong phase drop. The phases are linearly decreasing at low frequencies, reach an asymptotic value of $-130^{\circ}$ before they drop down due to the rail-on-rail-pad resonance at high frequencies.

\section{CALCULATED DEPENDENT COMPLIANCE FUNCTIONS OF SLAB TRACKS}

The frequency-dependent compliance functions of slab tracks have been calculated for some parameter variations. Figure 12 top and bottom shows for each variation the amplitude and phase function of the rail (left) and the track plate (right). If the height of the plate is varied between $t_{P}=0.15$ and $0.6 \mathrm{~m}$, there is an influence on the amplitudes of the track plate (relatively higher at high frequencies, Fig. 12a), but only a weak effect on the rail (small differences for the small phases, Fig 12b). The influence of the soil is stronger (Fig. 12c,d), particularly the low-frequency amplitudes and phases are higher for a soft soil. The influence is strongest for the track plate amplitudes which vary between $u=0.7$ and $4.210^{-9} \mathrm{~m} / \mathrm{N}$ and that is $u \sim v_{S}{ }^{-1.6} \sim G^{-0.8}$ almost indirect proportional to the stiffness $G$ of the soil. The phases of the track plate have a different decrease, the strongest for the softest soil, reach a common asymptote of $-90^{\circ}$, and fall further down at the highest frequencies. The latter is due to the rail pad of $k_{R}=60 \mathrm{kN} / \mathrm{mm}$. The influence of the rail pad is analysed in Fig. 12e,f. Soft rail pads result in a clear resonance of the rail at $85 \mathrm{~Hz}$ for $k_{R}=10 \mathrm{kN} / \mathrm{mm}, 120 \mathrm{~Hz}$ for $20 \mathrm{kN} / \mathrm{mm}$ and $145 \mathrm{~Hz}$ for $30 \mathrm{kN}$ (Fig. 12e). At the same frequency, the phase drops down 


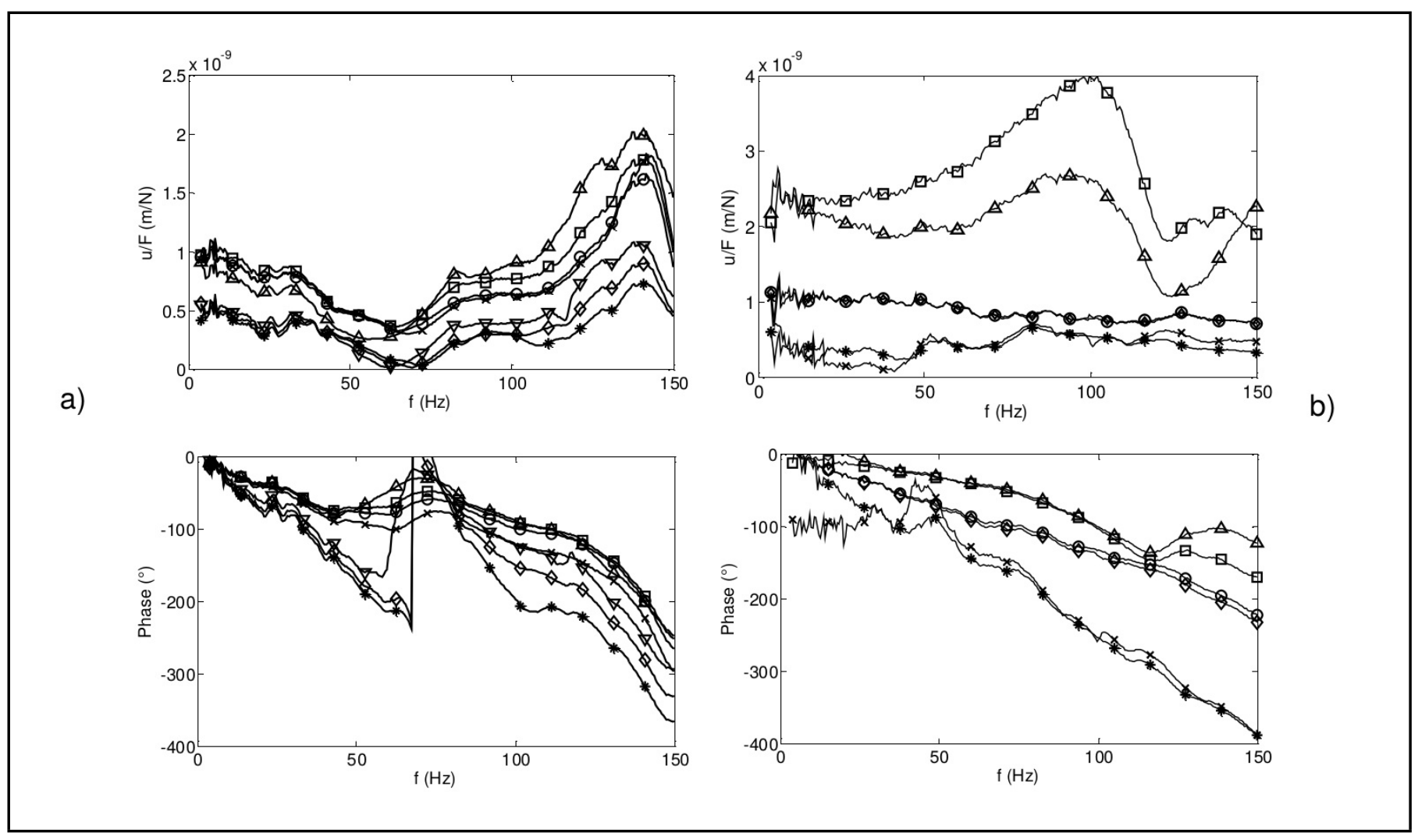

Figure 10. Compliance transfer functions (amplitude top, phase bottom) from unloaded hammer impact measurements. a) Different measurement points at site 7, and b) at site 3 , sleeper ( $\square$ right, $\triangle$ mid, $\nabla$ left), track plate $(\bigcirc$ right, $\times$ left), base layer $(\diamond$ right, $*$ left).

a)
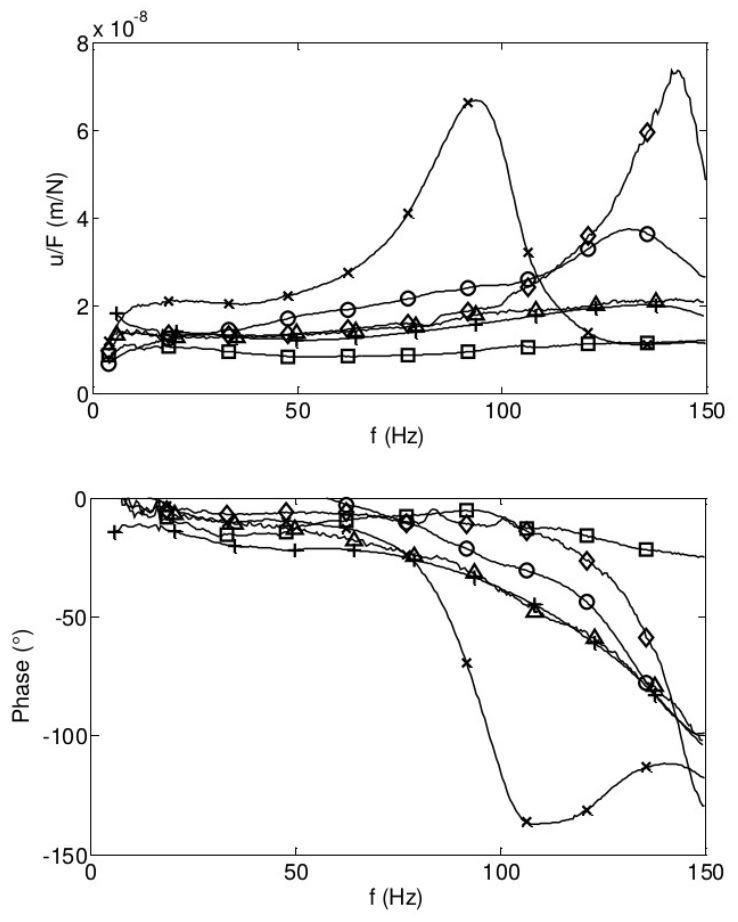

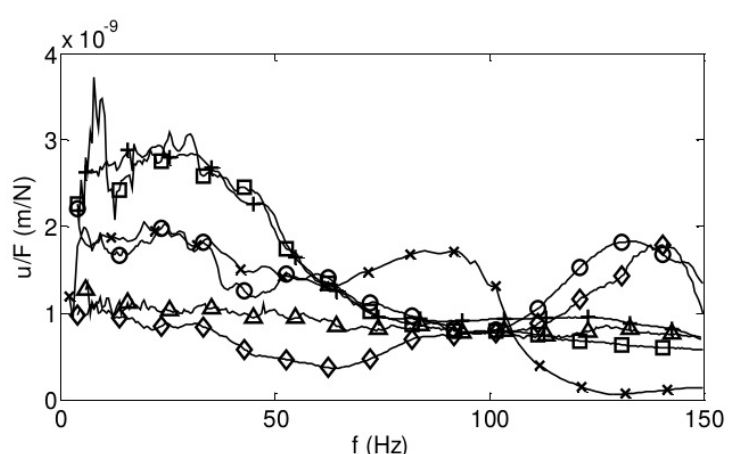

b)

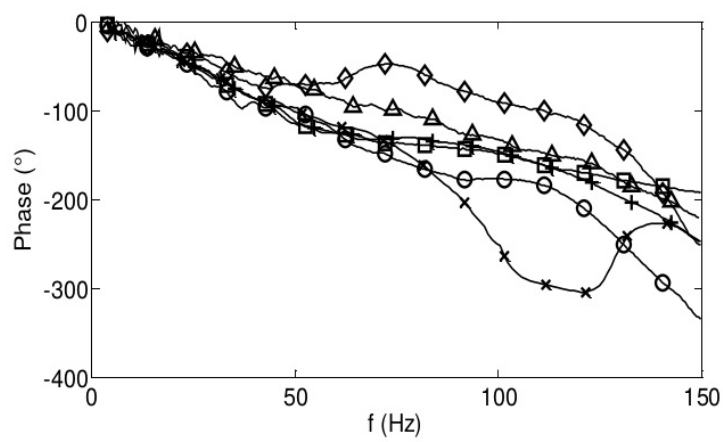

Figure 11. Compliance transfer functions (amplitude top, phase bottom) from unloaded hammer impact measurements. a) Rail points and b) sleeper or track plate points at different sites, $\square$ slab track, site $1, \bigcirc$ slab track, site $2, \triangle$ slab track, site $3,+$ slab track with stiff rail pads, site $5, \times$ slab track with soft rail pads, site $5 \mathrm{~b}, \diamond$ slab track, site 7 . 
a)
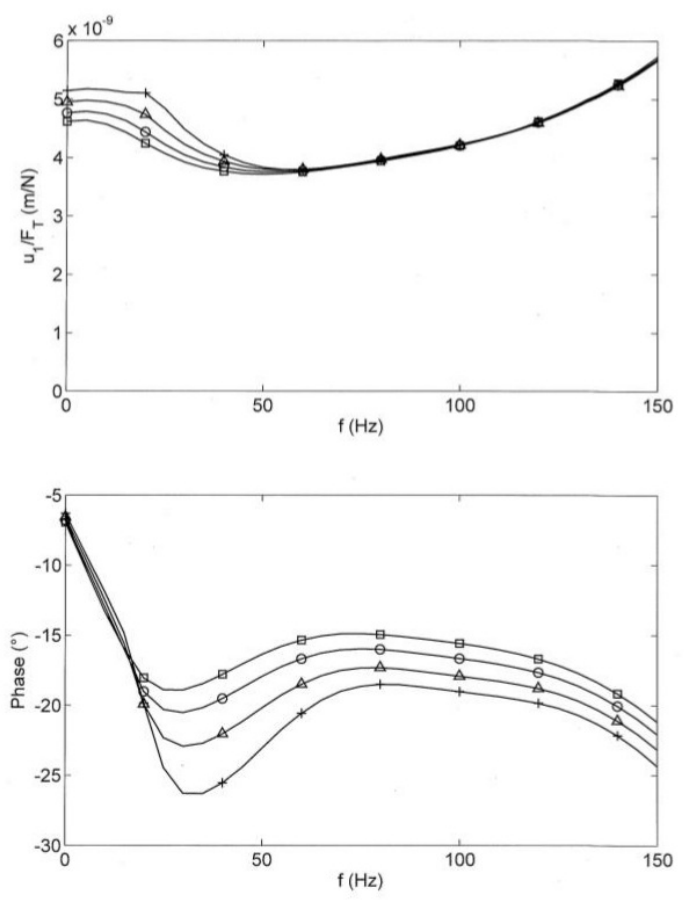

c)
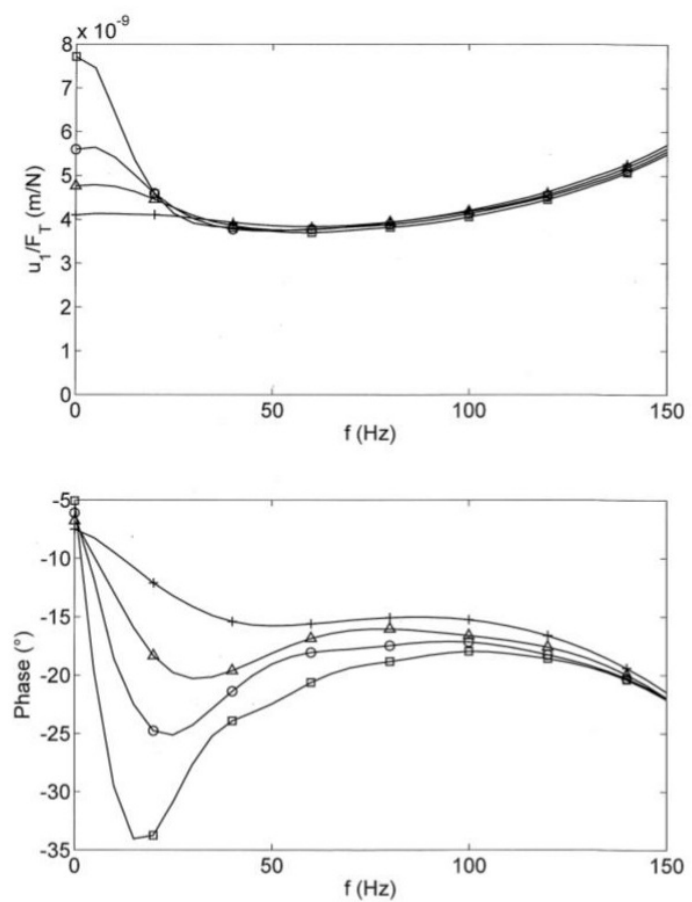

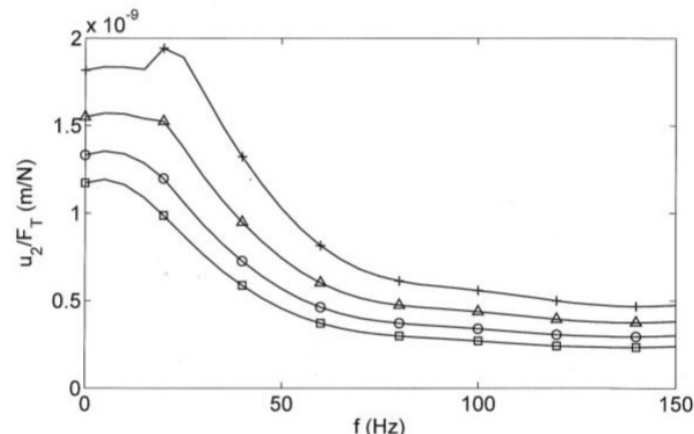

b)
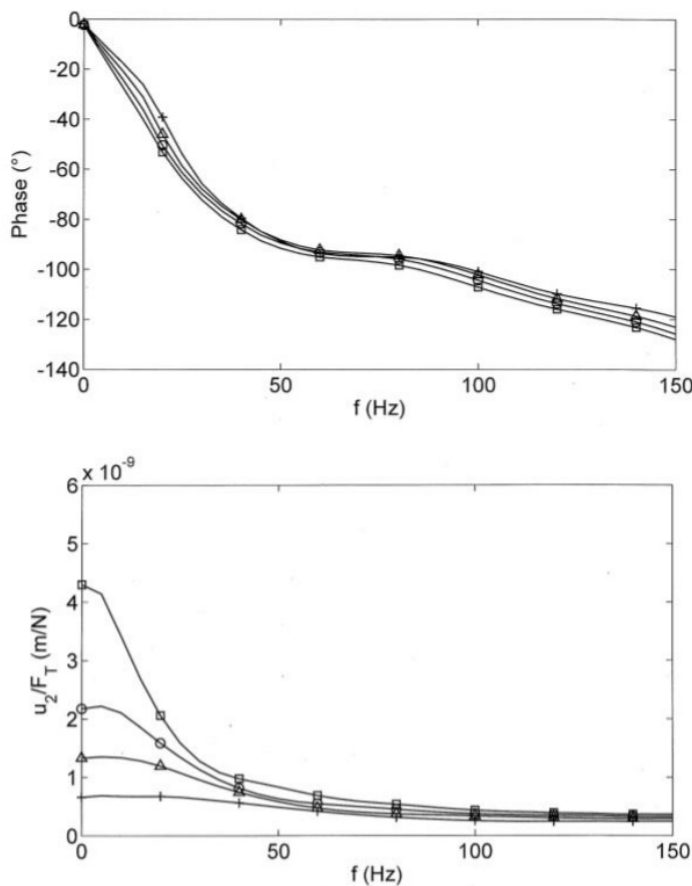

d)

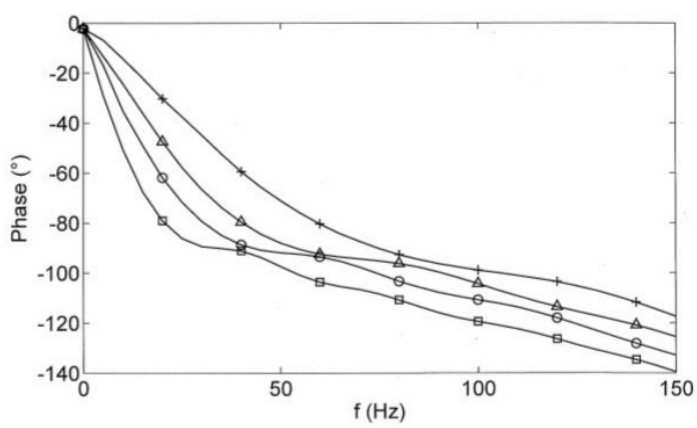

Figure 12. Calculated compliance transfer functions (amplitude top, phase bottom), a,c,e,g) of the rail, b,d,f,h) of the track plate. a),b) Different track plates $t_{P}$ $=\square 0.6, \bigcirc \underline{0.45}, \triangle 0.3,+0.15 \mathrm{~m}, \mathrm{c}, \mathrm{d})$ different soils $v_{S}=\square 100, \bigcirc 150, \underline{200}, \triangle 300 \mathrm{~m} / \mathrm{s}$. (Continued on the next page.)

strongly to $-130^{\circ}$. The resonances can also be seen at the track plate with smaller amplitudes and a strong phase drop from $-100^{\circ}$ to less than $-250^{\circ}$ (Fig. 12f). Finally, the damping of the rail pads has been varied in Fig. $12 \mathrm{~g}, \mathrm{~h}$. The resonance amplitudes of the rail are small for $D=0.2$ but still visible (Fig. 12g). The resonance can be completely hidden for the track-plate amplitudes (no amplification, Fig. 12h) and the track plate phases (continuous decrease, Fig. 12h bottom) for a rail pad damping of $D=0.2$ or higher.

The information from this parametric study has been used to find appropriate track models which represent the measure- ments well. Figures 13a,b show the results for six models which are close to the measured results of six sites (Fig. 11a,b). The agreement between theory and measurement is quite good for both, the rail and the track-plate displacements, and both, the amplitudes and the phases. Note, that the measured onesided hammer results must be reduced by a factor of 0.5 (rail) or 0.7 (track plate) to be compared with the theoretical results for a two-sided wheelset excitation. 
e)
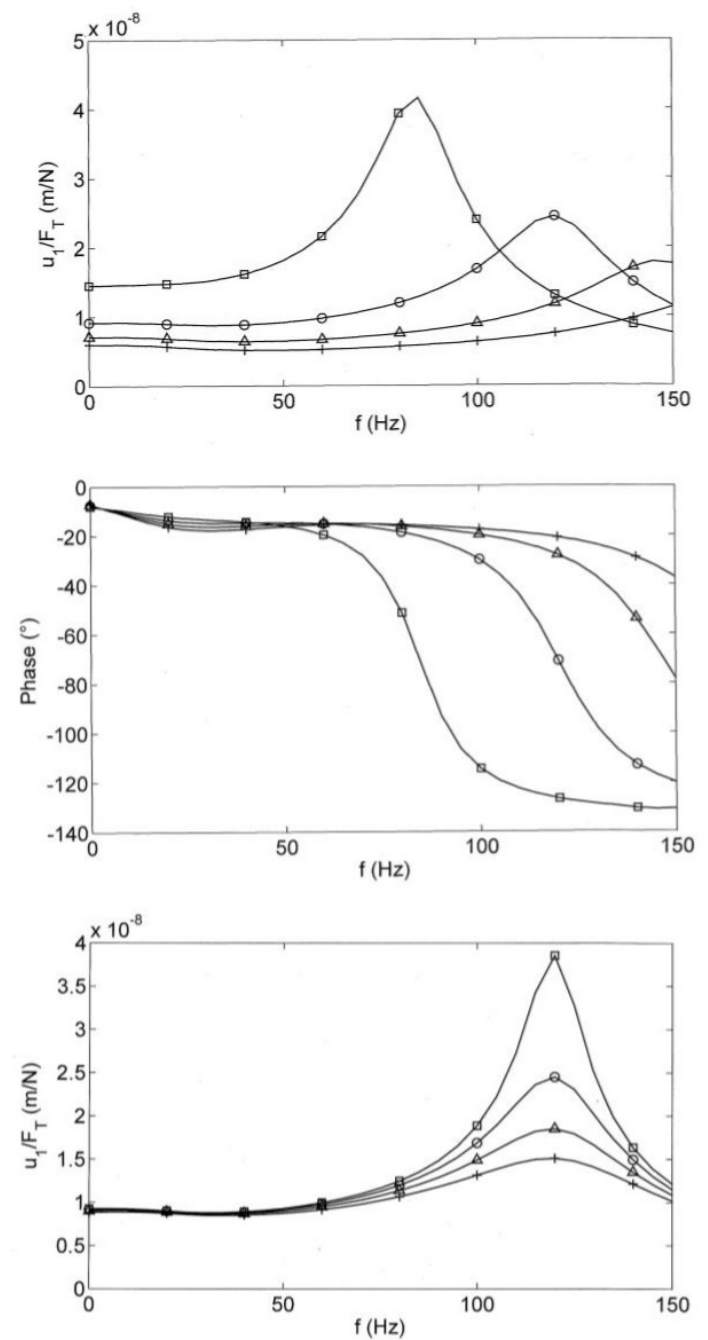

g)

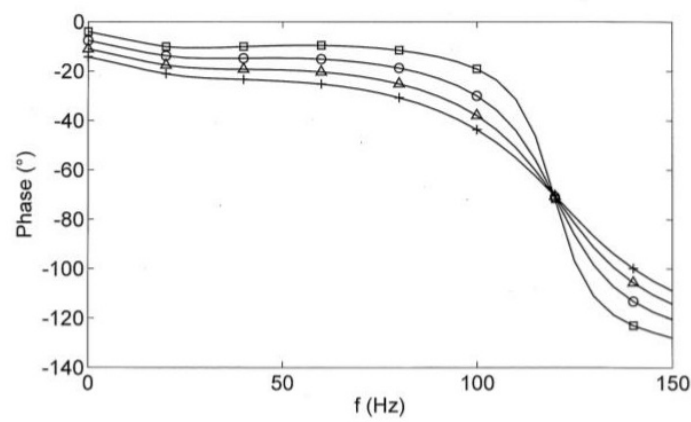

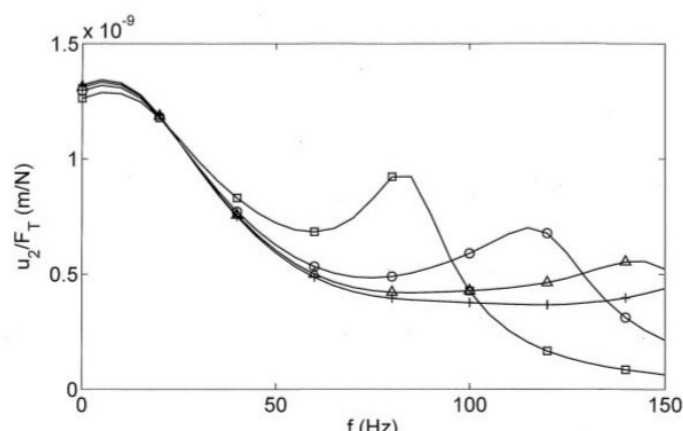

f)
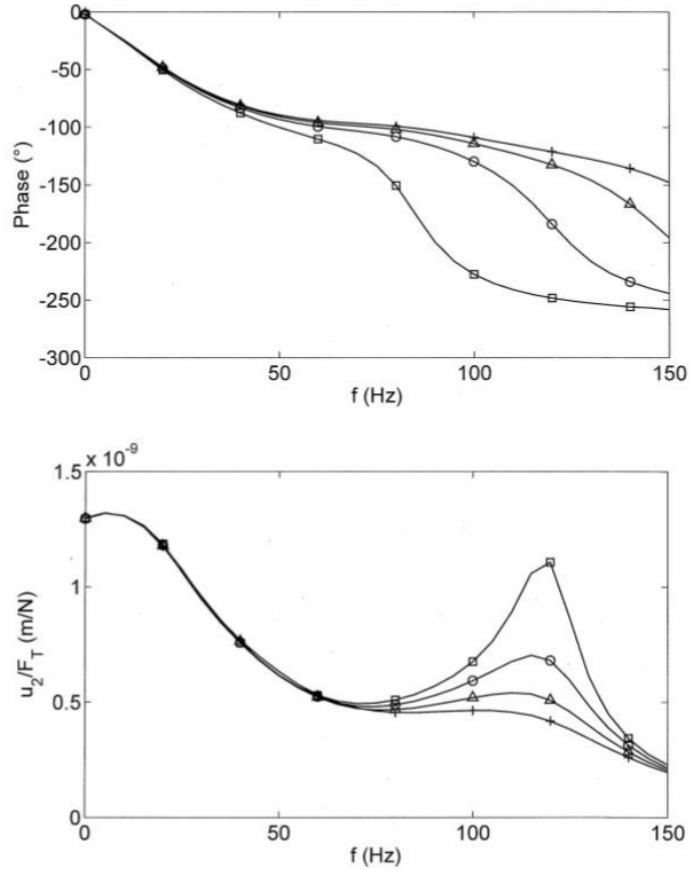

h)

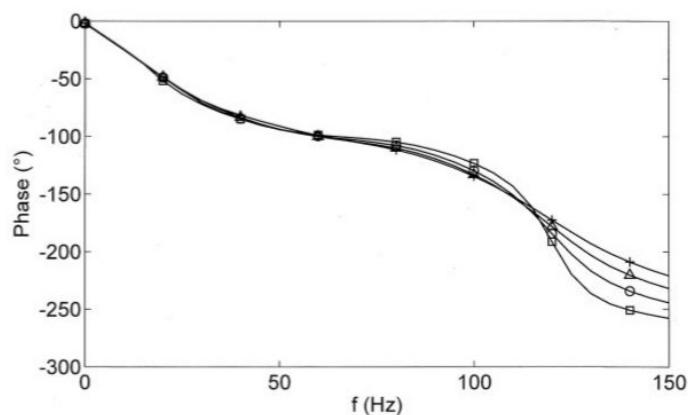

Figure 12. Continued: calculated compliance transfer functions (amplitude top, phase bottom), a,c,e,g) of the rail, b,d,f,h) of the track plate. e,f) different soft rail pads $k_{R}=\square 10, \bigcirc 20, \triangle 30,+40 \mathrm{kN} / \mathrm{mm}$ (standard $k_{R}=\underline{60} \mathrm{kN} / \mathrm{mm}$ ), g,h) different rail pad damping $D=\square 0.05, \bigcirc \underline{0.1}, \triangle 0.15,+0.2$.

\section{COMPARISON OF THEORY AND MEASUREMENT OF TRAIN AND HAMMER EXCITATION}

At first, the compliances measured by hammer impact (Fig. 11) are compared with the theoretical compliances for a wheelset excitation (Fig. 12). The measured track-plate compliances of 1 to $2.510^{-9} \mathrm{~m} / \mathrm{N}$ are well within the theoretical range of slab tracks on medium to stiff soils, if the one-sided amplitudes are reduced to the two-sided wheelset excitation $\left(0.5\right.$ to $\left.210^{-9} \mathrm{~m} / \mathrm{N}\right)$. The same theoretical amplitudes hold also for the passage of a single axle (Fig. 5a,b). The amplitudes for the passage of the whole train, when two bogies contribute to the axle displacement, are considerably higher at 0.2 to $0.3 \mathrm{~mm}$ per a $100 \mathrm{kN}$ axle load (Fig. 5c-f). These displacements correlate well with the measured track plate displacements under an ICE axle load of $160 \mathrm{kN}$, if a medium to medium stiff soil ( 150 to $200 \mathrm{~m} / \mathrm{s}$ wave velocity) has been assumed. In total all results agree quite well. The train passages match with a little less compliant slab track than the hammer impacts. This could be due to the stiffening effect of the static train load. Whereas the stiffening effect of the static load should be considered, the 


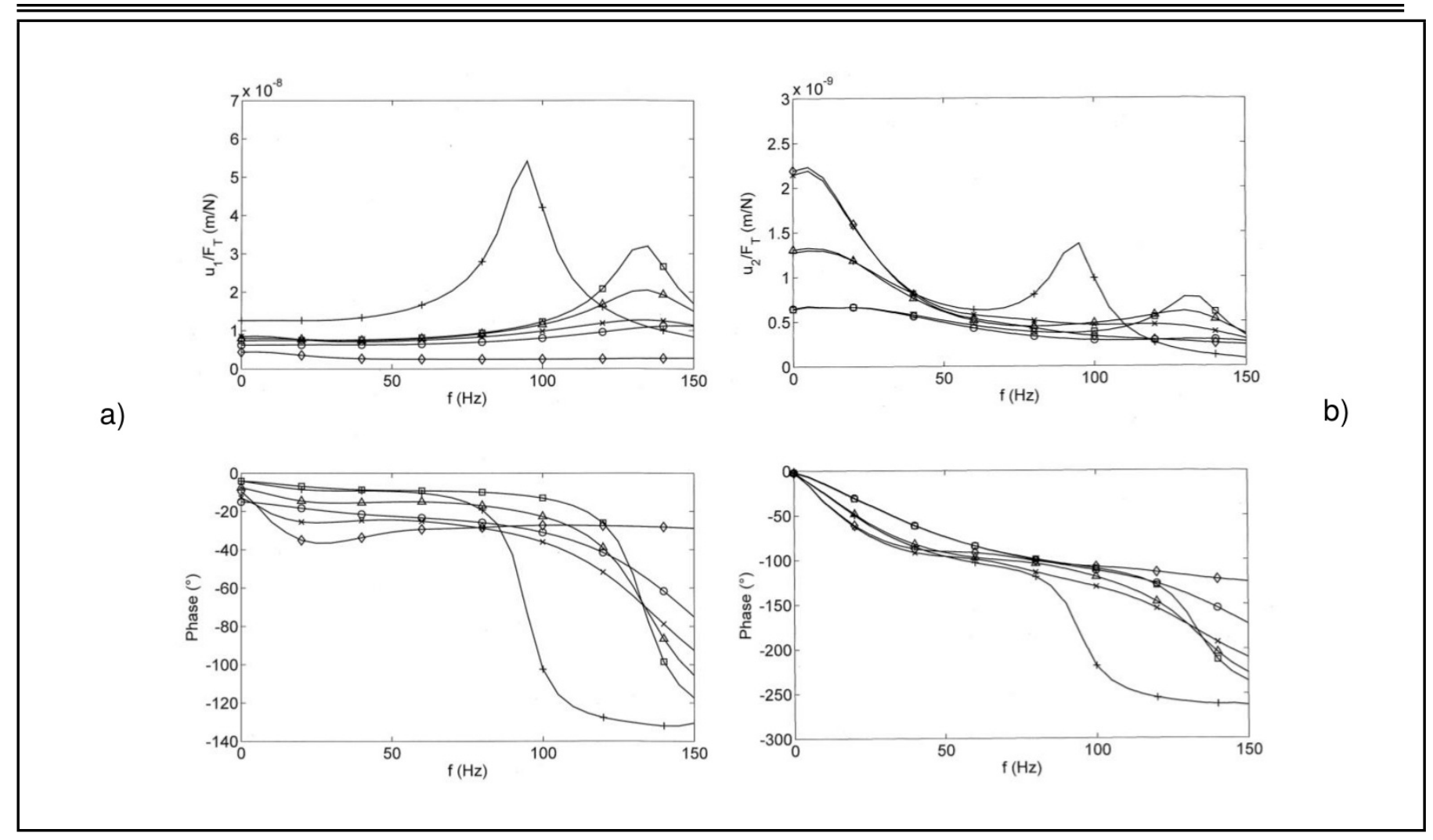

Figure 13. Calculated compliance transfer functions (amplitude top, phase bottom), adjusted parameters to compare with the different measurement situations (Fig. 10). $t_{P}=0.45 \mathrm{~m}, v_{S}=150-300 \mathrm{~m} / \mathrm{s}, k_{R}=12-100 \mathrm{kN} / \mathrm{mm}, \mathrm{D}=0.05-0.2$.

moving load effect can be neglected as the train speed is significantly lower than the Rayleigh wave velocity of the soil.

\section{CONCLUSION}

The calculation and measurement of several slab tracks have revealed the following characteristics. The displacements of the track plate highly depend on the stiffness of the soil. For typical wave velocities between 150 and $200 \mathrm{~m} / \mathrm{s}$ the displacements are between 0.2 and $0.3 \mathrm{~mm}$ per $100 \mathrm{kN}$ axle load. This correlates well with the measured displacements of 0.3 to $0.5 \mathrm{~mm}$ for an ICE train with $160 \mathrm{kN}$ axle load. The displacements of the rail are mainly ruled by the stiffness of the elastic rail pads. The measured value of $0.8 \mathrm{~mm}$ for the passage of a $100 \mathrm{kN}$ axle load correlates well with the static compliance of $1 \mathrm{~mm} / 100 \mathrm{kN}$ from the hammer excitation of many slab tracks. Some more specific items could be found from the measurements: Resonances, displacement amplitudes, amplitude changes (for damages), amplitude differences of different track elements, deflection shapes with different inter-axle and inter-bogie displacements. These characteristics from train passage and hammer impact measurements can be used to identify track properties such as very soft or rather stiff rail pads, elastic layers in floating slab tracks, an asphalt track or a ballast track, or to identify track damage and the repair effects. The measured track compliances can also be useful for the analysis of the vehicle-track-soil interaction and the determination of dynamic excitation loads.

\section{ANNEX 1. DETAILS OF THE MEASUREMENT SITES}

This article reports measurement results of 18 different track-soil systems at 12 different sites. Some details are given in Table 1. The slab tracks consist at least of a track plate and a base layer (site 5). Most slab tracks have an additional element which is a sleeper at sites 3,4 , and 7, or a base plate (a trough) at sites 1 and 2. At sites 1 and 2, there are sleepers integrated in the track plate. At site 6 , a floating slab track has been measured where the $6 \mathrm{~m}$ long track plates lie on an elastic rubber layer over a base plate and base layer. The typical dimensions of the track layers are $0.3 \mathrm{~m}$ for track plate and base layer, and if there is a base plate, then track plate and base plate have $0.15 \mathrm{~m}$ each.

Passages of ICE, IC regional and freight trains have been measured. The train type evaluated in this article have been underlined. For each site, the figures with the corresponding results are indicated in the last column.

\section{REFERENCES}

1 Esveld, C. Modern Railway Track, MRT-Productions, Delft, $2^{\text {nd }}$ edition, (2001).

2 Steenbergen, M., Metrikine, A. and Esveld, C. Assessment of design parameters of a slab track railway system from a dynamic viewpoint, Journal of Sound and Vibration, 306, 361-371, (2007). https://dx.doi.org/10.1016/j.jsv.2007.05.034

3 Fröhling, R. Deterioration of railway track due to dynamic vehicle loading and spatially varying track stiffness, Dissertation, University of Pretoria, (1997).

4 Berggren, E. Railway Track Stiffness - Dynamic Measurements and Evaluation for Efficient Maintenance, Doctoral Thesis, KTH Stockholm, (2009).

5 Bowness, D., Lock, A., Powrie, W., Priest, J. and Richards, D. Monitoring the dynamic displacements of railway track, 


\begin{tabular}{|c|c|c|c|c|c|}
\hline \multirow{2}{*}{ site } & \multicolumn{2}{|l|}{ track } & \multirow{2}{*}{$\begin{array}{l}\text { excitation } \\
\text { trains, hammer }\end{array}$} & \multirow{2}{*}{ specifics } & \multirow{2}{*}{ figure number } \\
\hline & type & structure & & & \\
\hline \multirow[t]{3}{*}{1} & \multirow{3}{*}{$\begin{array}{l}\text { slab } \\
\text { track }\end{array}$} & \multirow{3}{*}{$\begin{array}{l}\text { integrated sleeper, track plate, } \\
\text { base plate, base layer, soil }\end{array}$} & \multirow{3}{*}{$\underline{\mathrm{ICE}}, \mathrm{IC}$, freight trains, hammer } & intact track & $2,6 a, 9,11$ \\
\hline & & & & damaged & $7 \mathrm{~b}$ \\
\hline & & & & after repair & $7 \mathrm{a}$ \\
\hline 2 & $\begin{array}{l}\text { slab } \\
\text { track }\end{array}$ & $\begin{array}{l}\text { integrated sleeper, track plate, base } \\
\text { plate, base layer, soil }\end{array}$ & $\underline{\text { ICE}}, \mathrm{IC}$, freight trains, hammer & & $6 b, 11$ \\
\hline 3 & $\begin{array}{l}\text { slab } \\
\text { track }\end{array}$ & sleeper, track plate, base layer, soil & 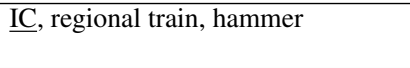 & & $6 \mathrm{c}, 10 \mathrm{~b}, 11$ \\
\hline 4 & $\begin{array}{l}\text { slab } \\
\text { track }\end{array}$ & sleeper, track plate, base layer, soil & $\underline{\text { ICE}}, \mathrm{IC}$, regional and freight trains & & $6 \mathrm{~d}$ \\
\hline \multirow[t]{3}{*}{5} & \multirow{3}{*}{$\begin{array}{l}\text { slab } \\
\text { track }\end{array}$} & \multirow{2}{*}{ track plate, base layer, soil } & \multirow{3}{*}{$\begin{array}{l}\text { ICE, IC, regional and freight trains, } \\
\text { hammer }\end{array}$} & concrete track plate & $6 \mathrm{e}, 11$ \\
\hline & & & & soft rail pad & 11 \\
\hline & & sleeper, track plate, base layer, soil & & asphalt track plate & $6 f$ \\
\hline \multirow[t]{2}{*}{6} & \multirow{2}{*}{$\begin{array}{l}\text { slab } \\
\text { track }\end{array}$} & \multirow{2}{*}{$\begin{array}{l}\text { track plates, elastic layer, base } \\
\text { plate, base layer, soil }\end{array}$} & short ICE & normal soil & $6 g$ \\
\hline & & & short $\overline{\mathrm{ICE}}$ & stiff soil & $6 \mathrm{~h}$ \\
\hline \multirow[t]{2}{*}{7} & $\begin{array}{l}\text { slab } \\
\text { track }\end{array}$ & sleeper, track plate, base layer, soil & \multirow[t]{2}{*}{$\underline{\mathrm{IC}}$, regional trains, hammer } & & $3,7 \mathrm{c}, 10 \mathrm{a}, 11$ \\
\hline & $\begin{array}{l}\text { ballast } \\
\text { track }\end{array}$ & sleeper, ballast, soil, & & & $7 \mathrm{~d}$ \\
\hline \multirow[t]{2}{*}{8} & \multirow{2}{*}{$\begin{array}{l}\text { ballast } \\
\text { track }\end{array}$} & \multirow{2}{*}{ sleeper, ballast, soil, (switch) } & \multirow{2}{*}{ ICE, $\underline{\text { IC }}$, regional and freight trains } & without under-sleeper pads & $7 \mathrm{e}$ \\
\hline & & & & with under-sleeper pads & $7 f$ \\
\hline \multirow[t]{2}{*}{9} & \multirow{2}{*}{$\begin{array}{l}\text { ballast } \\
\text { track }\end{array}$} & \multirow{2}{*}{ sleeper, ballast, soil, (switch) } & \multirow{2}{*}{$\underline{\text { IC, }}$, regional and freight trains } & without under-sleeper pads & $7 g$ \\
\hline & & & & with under-sleeper pads & $7 \mathrm{~h}$ \\
\hline 10 & $\begin{array}{l}\text { ballast } \\
\text { track }\end{array}$ & sleeper, ballast, soil, (switch) & $\underline{\text { ICE}}$, regional and freight trains & Switch & $8 \mathrm{a}$ \\
\hline 11 & $\begin{array}{l}\text { ballast } \\
\text { track }\end{array}$ & sleeper, ballast, soil, (switch) & $\underline{\text { ICE}}$, regional and freight trains & Switch & $8 \mathrm{~b}$ \\
\hline 12 & $\begin{array}{l}\text { ballast } \\
\text { track }\end{array}$ & sleeper, ballast, soil, (switch) & $\underline{\text { ICE}}$, regional and freight trains & Switch & $8 \mathrm{c}, 8 \mathrm{~d}$ \\
\hline
\end{tabular}

Proceedings of the Institution of Mechanical Engineers, Part F: Journal of Rail and Rapid Transit, 221, 13-22, (2007). https://dx.doi.org/10.1243/0954409JRRT51

6 Zhu, S. and Cai, C. Interface damage and its effect on vibrations of slab track under temperature and vehicle dynamic loads, International Journal Non-Linear Mechanics, 58, 222-232, (2014). https://dx.doi.org/10.1016/j.ijnonlinmec.2013.10.004

7 Ren, J., Yang, R., Wang, P., Dai, F. and Yan, X. Influence of contact loss underneath concrete underlayer on dynamic performance of prefabricated concrete slab track, Rail and Rapid Transport, 231 (3), 345-358, (2017). https://dx.doi.org/10.1177/0954409716630339

8 Oregui, M., Li, Z. and Dollevoet, R. Identification of characteristic frequencies of damaged railway tracks using field hammer test measurements, Mechanical Systems Signal Processing, 54, 224-242, (2015). https://dx.doi.org/10.1016/j.ymssp.2014.08.024

9 Auersch, L. and Said, S. Track-soil dynamics - Calculation and measurement of damaged and repaired slab tracks, Transportation Geotechnics, 12, 1-14, (2017). https://dx.doi.org/10.1016/j.trgeo.2017.06.003

10 Berggren, E., Kaynia, A. and Dehlbom, B. Identification of substructure properties of railway tracks by dynamic stiffness measurements and simulations, Journal of Sound and Vibration, 329 (19), 3999-4016, (2010). https://dx.doi.org/10.1016/j.jsv.2010.04.015

11 Coelho, B., Hölscher, P., Priest, J., Powrie, W. and Barends, F. An assessment of transition zone performance, Proceedings of the IMechE Part F, Journal of Rail and Rapid Transit, 225, 129-139, (2011). https://dx.doi.org/10.1177/09544097JRRT389
12 Selig, E. and Waters, J. Track Geotechnology and Substructure Management, Telford, London, (1994). https://dx.doi.org/10.1680/tgasm.20139

13 Picoux, B., Rotinat, R., Regoin, J. and Le Houedec, D. Prediction and measurements of vibrations from a railway track lying on a peaty soil, Journal of Sound and Vibration, 267, 575-589, (2003). https://dx.doi.org/10.1016/S0022$460 \times(03) 00725-9$

14 Cui, Y., Lamas-Lopez, F., Trinh, V., Calon, N., Costa d'Aguiar, S., Dupla, J., Tang, A., Canou, J. and Robinet, A. Investigation of interlayer soil behaviour by field monitoring, Transportation Geotechnics, 1 (3), 91-105, (2014). https://dx.doi.org/10.1016/j.trgeo.2014.04.002

15 Le Pen, L., Watson, G., Powrie, W., Yeo, G., Weston, P., Roberts, C. The behaviour of railway level crossings: Insights through field monitoring. Transportation Geotechnics, 1 (4), 201-213, (2014). https://dx.doi.org/10.1016/j.trgeo.2014.05.002

16 Costa d'Aguiar, S., Arlaud, E., Potvin, R., Laurans, E. and Funfschilling, C. Railway transitional zones: a case history from ballasted to ballastless track. International Journal of Railway Technology, 3 (1), 37-61, (2014). https://dx.doi.org/10.4203/ijrt.3.1.2

17 de Man, A. Dynatrack: a survey of dynamic railway track properties and their quality, $\mathrm{PhD}$ Thesis, Delft University, (2002).

18 Kaewunruen, S., Remennikov, A. Field trials for dynamic characteristics of railway track and its components using impact excitation technique. NDT \& E International, 40 (7), 510-519, (2007). https://dx.doi.org/10.1016/j.ndteint.2007.03.004 
19 Maldonado, M. Vibrations dues au passage d'un tramway - mesures expérimentales et simulations numériques, $\mathrm{PhD}$ Thesis, Ecole Centrale, Nantes, (2008).

20 Galvin, P. and Dominguez, J. Experimental and numerical analyses of vibrations induced by high-speed trains on the Cordoba-Malaga line, Soil Dynamics and Earthquake Engineering, 29, 641-657, (2009). https://dx.doi.org/10.1016/j.soildyn.2008.07.001

21 Alves Costa, P. Vibrações do sistema via-maciço induzidas por tráfego ferroviário - modelação numérica e validação experimental, PhD Thesis, University of Porto, Portugal, (2011).

22 Romero A. Predicción, medida experimental y evaluación de las vibraciones producidas por el tráfico ferroviario, PhD Thesis, University of Sevilla, (2012).

23 Arlaud, E., Costa d'Aguiar S., Balmes E. Receptance of railway tracks at low frequency: Numerical and experimental approaches, Transportation Geotechnics, 9, 1-16, (2016). https://dx.doi.org/10.1016/j.trgeo.2016.06.003

24 Sato, Y., Morimura, T. and Watanabe, S. Theoretical analyses and experimental results on track moduli with use of the wheelset drop test. Vehicle System Dynamics, 24, 164-179, (1995). https://dx.doi.org/10.1080/00423119508969623

$25 \mathrm{Li}, \mathrm{M}$. and Berggren, E. A study of the effect of global track stiffness and its variations on track performance: simulation and measurement, Journal of Rail and Rapid Transit, 224, 375-382, (2010). https://dx.doi.org/10.1243/09544097JRRT361

26 Kouroussis, G., Verlinden, O., Conti, C. Free field vibrations caused by high-speed lines: Measurements and time domain simulation, Soil Dynamics and Earthquake Engineering, 31, 692-707, (2011). https://dx.doi.org/10.1016/j.soildyn.2010.11.012

27 Zhai, W., Wei, K., Song, X. and Shao, M. Experimental investigation into ground vibrations induced by very high speed trains on a non-ballasted track, Soil Dynamics and Earthquake Engineering, 72, 24-36, (2015). https://dx.doi.org/10.1016/j.soildyn.2015.02.002

28 Auersch, L. Simultaneous measurements of the vehicle, track, and soil vibrations at a surface, bridge, and tunnel railway line, Shock and Vibration, ID 1959286: 1-18, (2017). https://dx.doi.org/10.1155/2017/1959286

29 Milne, D., Le Pen, L., Thompson, D. and Powrie W. Automated processing of railway track deflection signals obtained from velocity and accelerometer measurements, Rail and Rapid Transport, 232, 2097-2110, (2018). https://dx.doi.org/10.1177/0954409718762172

30 Sheng, X., Jones, C., Thompson D. A theoretical study on the influence of the track on train-induced ground vibration, Journal of Sound and Vibration, 272, 909-936, (2004). https://dx.doi.org/10.1016/S0022-460X(03)00781-8

31 Lombaert, G., Degrande G, Vanhauwere B, Vandeborght $\mathrm{B}$, Francois $\mathrm{S}$. The control of ground-borne vibrations from railway traffic by means of continuous floating slabs. Journal of Sound and Vibration, 297, 946-961, (2006). https://dx.doi.org/10.1016/j.jsv.2006.05.013
32 Auersch, L. The dynamic behaviour of slab tracks on homogeneous and layered soils and the reduction of ground vibration by floating slab tracks. Journal of Engineering Mechanics, 138 (8), 923-933, (2012). https://dx.doi.org/10.1061/(ASCE)EM.19437889.0000407

33 Auersch, L. Dynamics of the railway track and the underlying soil: the boundary-element solution, theoretical results and their experimental verification. Vehicle System Dynamics, 43 (9), 671-695, (2005). https://dx.doi.org/10.1080/00423110412331307663

$34 \mathrm{Ju}$, S., Lin, H. Experimentally investigating finite element accuracy for ground vibrations induced by highspeed trains. Engineering Structures, 30, 733-746, (2008). https://dx.doi.org/10.1016/j.engstruct.2007.05.019

35 Kouroussis, G. Modélisation des effets vibratoirs du traffic ferroviaire sur l'environnement, Thèse de doctorat, Université de Mons, (2009).

36 Connolly, D. Ground borne vibrations from high-speed trains, PhD Thesis, University of Edinburgh, (2013).

37 Takemiya, H. Ground vibrations alongside tracks induced by high-speed trains: prediction and mitigation. In V. Krylov (Ed.), Noise and vibration from high-speed trains. Thomas Telford, London, 2001, 347-391.

38 Galvin, P., Francois, S., Schevenels, M., Bongini, E., Degrande, G. and Lombaert, G. A 2.5D coupled FE-BE model for the prediction of railway induced vibrations, Soil Dynamics and Earthquake Engineering, 30, 1500-1512, (2010). https://dx.doi.org/10.1016/j.soildyn.2010.07.001

39 Alves Costa, P., Calcada, R. and Cardoso A. Track-ground vibrations induced by railway traffic - In situ measurements and validation of a 2.5D FEM-BEM model, Soil Dynamics and Earthquake Engineering, 32, 111-128, (2012). https://dx.doi.org/10.1016/j.soildyn.2011.09.002

40 Auersch, L. and Said, S. Measurement of slab track behaviour at different sites, Proc. $26^{\text {th }}$ International Congress on Sound and Vibration, Montreal, 2019, 1-8 (USB-Stick).

41 Auersch, L. and Said, S. Comparison of different dispersion evaluation methods and a case history with the inversion to a soil model, related admittance functions, and the prediction of train induced ground vibration. Journal of Near Surface Geophysics, 13 (2), 127-142, (2015). https://dx.doi.org/10.3997/1873-0604.2015011

42 Auersch L. Wave propagation in layered soil, theoretical solution in wavenumber domain and experimental results of hammer and railway traffic excitation. Journal of Sound and Vibration, 173, 233-264, (1994). https://dx.doi.org/10.1006/jsvi.1994.1228

43 Kausel, E. and Roesset, J. Stiffness matrices for layered soils, Bulletin of the Seismological Society of America, 71, 1743-1761, (1981).

44 Wolf, J. Dynamic Soil-Structure Interaction, Prentice-Hall, Englewood Cliffs, New Jersey, (1985). 